\title{
Estimation of Uncertainties for a Supersonic Retro- Propulsion Model Validation Experiment in a Wind Tunnel
}

\author{
Matthew N. Rhode* \\ NASA Langley Research Center, Hampton, VA 23681 \\ William L. Oberkampf ${ }^{\dagger}$ \\ W. L. Oberkampf Consulting, Austin, TX 78633
}

\begin{abstract}
A high-quality model validation experiment was performed in the NASA Langley Research Center Unitary Plan Wind Tunnel to assess the predictive accuracy of computational fluid dynamics (CFD) models for a blunt-body supersonic retro-propulsion configuration at Mach numbers from 2.4 to 4.6. Static and fluctuating surface pressure data were acquired on a 5-inch-diameter test article with a forebody composed of a sphericallyblunted, 70-degree half-angle cone and a cylindrical aft body. One non-powered configuration with a smooth outer mold line was tested as well as three different powered, forward-firing nozzle configurations: a centerline nozzle, three nozzles equally spaced around the forebody, and a combination with all four nozzles. A key objective of the experiment was the determination of experimental uncertainties from a range of sources such as random measurement error, flowfield non-uniformity, and model/instrumentation asymmetries. This paper discusses the design of the experiment towards capturing these uncertainties for the baseline non-powered configuration, the methodology utilized in quantifying the various sources of uncertainty, and examples of the uncertainties applied to non-powered and powered experimental results. The analysis showed that flowfield nonuniformity was the dominant contributor to the overall uncertainty - a finding in agreement with other experiments that have quantified various sources of uncertainty.
\end{abstract}

\section{Nomenclature}

Symbols

$\mathrm{C}_{\mathrm{p}} \quad$ pressure coefficient, $=\left(p-p_{\infty}\right) / q_{\infty}$

$\overline{C_{p}} \quad$ average pressure coefficient of two measurements from a run pair, per Eqn. 1

$\mathrm{C}_{\mathrm{T}} \quad$ thrust coefficient, $=F /\left(q_{\infty} S_{\text {ref }}\right)$

$\Delta \mathrm{C}_{\mathrm{p}} \quad$ residual pressure coefficient of two measurements from a run pair, per Eqn. 2

$\mathrm{F} \quad$ nozzle thrust, lbf

$\mathrm{L}$ total number of data records used in the calculation of variance

M Mach number

$\mathrm{N}$ total number of residuals used in the calculation of variance

p pressure, psia or psfa

q dynamic pressure, psfa

$\mathrm{r}, \theta$ pressure port location in model-fixed polar coordinate system, in, deg

$\mathrm{R}^{2} \quad$ correlation-of-fit metric for least-squares regression

$\mathrm{Re} \quad$ unit Reynolds number, $1 / \mathrm{ft}$

$\mathrm{S}_{\text {ref }} \quad$ model reference area (cross-sectional area), $\mathrm{ft}^{2}$

$\mathrm{T}$ temperature, ${ }^{\circ} \mathrm{R}$

$\mathrm{X}, \mathrm{Y}, \mathrm{Z}$ model location in test section coordinate axes, in

$\alpha_{\mathrm{T}} \quad$ model total angle of attack, deg

\footnotetext{
* Aerospace Engineer, Aerothermodynamics Branch, Mail Stop 408A, AIAA Senior Member.

${ }^{\dagger}$ Consultant, wloconsulting@gmail.com, AIAA Fellow.
} 
pressure port health status flag

$\phi \quad$ model roll angle in wind tunnel coordinates, deg

$\sigma \quad$ sample standard deviation calculated from residuals

$\sigma^{2} \quad$ sample variance calculated from residuals

\section{Subscripts/Superscripts}

i index referring to pressure port in the calculation of average and residual pressure coefficients

$\mathrm{j}$ index referring to angle of attack in the calculation of average and residual pressure coefficients

$\mathrm{k} \quad$ index referring to residual in the calculation of variance

$\mathrm{m}$ total number of angles of attack considered in a sequence of run pair comparisons

$\mathrm{q}$ index referring to data record in the calculation of the total number of residuals, $N$

$\mathrm{r} \quad$ superscript denoting the first run in a run pair

$\mathrm{s} \quad$ superscript denoting the second run in a run pair

$\mathrm{T} \quad$ stagnation or total conditions

$\infty \quad$ freestream conditions

$\begin{array}{ll}\text { Abbreviations } \\ \text { AMS } & \text { Angle Measurement System } \\ \text { ANSI } & \text { American National Standards Institute } \\ \text { CFD } & \text { Computational Fluid Dynamics } \\ \text { DCV } & \text { Digital Control Valve } \\ \text { DESL } & \text { Data Engineering Scripting Language } \\ \text { DOE } & \text { Design of Experiments } \\ \text { EDL } & \text { Entry, Descent, and Landing } \\ \text { ESP } & \text { Electronically-Scanned Pressure } \\ \text { ETDD } & \text { Exploration Technology Development and Demonstration Program } \\ \text { ISO } & \text { International Organization for Standardization } \\ \text { JCEAP } & \text { Joint Computational/Experimental Aerodynamics Program } \\ \text { LaRC } & \text { Langley Research Center } \\ \text { NASA } & \text { National Aeronautics and Space Administration } \\ \text { OML } & \text { Outer Mold Line } \\ \text { PCU } & \text { Pressure Calibration Unit } \\ \text { RTD } & \text { Resistance Temperature Detector } \\ \text { SRP } & \text { Supersonic Retro-Propulsion } \\ \text { UPWT } & \text { Unitary Plan Wind Tunnel }\end{array}$

\section{Introduction}

$\mathrm{R}$ ecent system architecture studies for human and advanced robotic missions to Mars [1] have identified future deceleration technologies as a crucial element for entry, descent, and landing (EDL), given the inability of current parachute systems to deliver the large payloads required for these missions due to constraints on parachute size, materials, and performance. One of the technologies showing promise is supersonic retro-propulsion (SRP), or the use of propulsive thrust directed into the oncoming supersonic freestream flow to decelerate a vehicle during flight [2]. SRP has recently become a focus area of the EDL project within NASA's Exploration Technology Development and Demonstration (ETDD) Program, with present studies to investigate not only hardware integration and system performance, but the complex flowfield as well. SRP results in unsteady jet plume/shock interactions, shear layers, embedded pockets of subsonic flow, and large areas of recirculation - all of which can be difficult to predict accurately using computational fluid dynamics (CFD) codes [3]. Therefore, validation of the CFD tools and methodologies is essential for modeling SRP aerodynamics and aerothermodynamics, and thus continuing to mature SRP technologies. However, data that might be used for validation purposes were found to be limited to experimental investigations from decades ago. These older studies were typically exploratory in nature, and the historical reports often lacked key pieces of information to allow comparisons with modern CFD codes [4,5]. Therefore a modern SRP experiment was proposed with two goals in mind. The first was to conduct a high-quality validation experiment to determine the predictive accuracy of CFD models. That is, a wind tunnel experiment was 
designed, executed, and analyzed for the purpose of determining the ability of a CFD model to simulate the flowfield around the SRP geometry, with and without thrust. The second goal was to obtain experimental surface pressure data and flowfield imagery for a representative planetary configuration, with and without thrust from the forward-facing supersonic nozzles, to better understand the fundamental fluid dynamics phenomena associated with SRP and to examine effects of nozzle location and thrust setting.

The design of the SRP experiment followed a number of guidelines proposed over the past decade for CFD validation experiments [6], as discussed in detail by Berry [7]. One of these guidelines is that the experiment should be deliberately designed to acquire data for estimating both the random and systematic components of uncertainty [8]. These uncertainty estimates, typically reported at a $95 \%$ confidence level, provide a metric of comparison between the computational and experimental results. It is important to exercise the relevant variables present in an experiment, where possible, and obtain uncertainty information other than just replication of a set of conditions. For wind tunnel experiments, uncertainty and spatial non-uniformity in the flow conditions can be a significant, if not the dominant, contributor to the overall uncertainty of a quantity of interest [9]. Additionally, deviations from the ideal surface geometry can alter a measurement, as can instrumentation installation effects, such as a leaking pressure port. These items cannot be addressed simply through analysis of the data repeatability; they must be actively varied to capture their effects within the test data and thus allow the estimation of the associated uncertainties. The present investigation follows this course, utilizing the methodology discussed in [10-13].

This paper discusses the approach used to estimate the pressure coefficient uncertainties in a SRP CFD model validation experiment performed in the NASA Langley Research Center Unitary Plan Wind Tunnel (UPWT) Test Section 2 at Mach numbers of 2.4, 3.5, and 4.6 [14,15]. Descriptions are given of the facility, test article, and instrumentation; and details are provided about the methodology and procedural steps used to estimate the various components of uncertainty for a non-powered, smooth outer mold line (OML) SRP configuration. Applications of the estimated uncertainties are shown and discussed for both non-powered and powered conditions, and the findings are summarized.

\section{Approach to Experimental Uncertainty Quantification}

The standard technique for estimating experimental measurement error is the International Organization of Standardization (ISO) technique described in the Guide to the Expression of Uncertainty in Measurement (GUM) $[16,17]$ and the American National Standards Institute (ANSI) report [18]. The ISO/ANSI technique has also been described in detail in certain disciplines, such as wind tunnel testing $[19,20]$. The technique is primarily concerned with the estimation of uncertainty in the measurement of a fixed quantity that is referred to as the true value. Within this framework, uncertainties are not categorized according to the traditional terms random and systematic, but according to the method which is used to characterize an uncertainty. The ISO/ANSI technique divides uncertainties into:

\section{Type A: uncertainties that are evaluated using a statistical analysis of a collection or ensemble of} observations.

Type B: uncertainties that are evaluated by means other than a statistical analysis of a collection or ensemble of observations.

The combined standard uncertainty of a quantity (the result of a number of other measured quantities) is the positive square root of a sum of terms. The terms are the variances or covariances of the other measured quantities weighted according to how the measurement result varies with changes in these quantities. The fact that Type B uncertainties are supposed to come from "other than statistical" means, does not deter the ISO/ANSI approach from using statistical analysis anyway.

Because of concerns with the ability of the traditional technique to estimate correlated systematic uncertainties, a different approach was used in the present experiment. The methodology used was an entirely statistical approach that is based on analyzing comparisons of multiple measurements of quantities of interest. It is usually referred to as statistical design of experiments (DOE) because it analyzes the final measured result of the quantities of interest, based on specially designed sampling techniques. The methodology has been used by the statistical community for at least the last four decades [21-23]. In the DOE approach, one identifies various classes of uncertainty sources that are believed to contribute to the combined (or total) uncertainty in the final quantities of interest. Then experimental conditions are carefully chosen (i.e., sampled) to quantify the statistical contribution that each of these sources contributes to the final quantities of interest. The approach uses replication, randomization, and blocking techniques 
in the design of the sample data collected in an experiment [24,25], and has been widely used in analyzing data from many fields - for example, production process control, system and component reliability, environmental statistics, biostatistics, medication testing, and epidemiology. This approach, however, has seen limited use in validation experiments. References $[8,10-13]$ have used this technique several times in wind tunnel validation experiments and compared it with the results obtained from the ISO/ANSI method. They have found that the random component of uncertainty, i.e., uncertainty computed by comparing a large number of replications of the experiment, compare well with the ISO/ANSI approach. However, the total estimated experimental uncertainty using the DOE technique has been found to be significantly greater than that estimated by the ISO/ANSI method. With the ISO/ANSI approach, the analyst must make assumptions about which individual uncertainty sources are present (as opposed to the broader classes of uncertainty sources in the DOE technique) as well as the relative magnitudes of those uncertainties and their correlations and interactions. This information can often be incomplete or in some cases guesswork, particularly for the correlations among systematic uncertainties, and result in erroneous estimates of the total uncertainty. The DOE methodology obtains the uncertainty information directly from the measurements without any of the aforementioned assumptions, provided that the experiment design allows these uncertainty classes to be exercised, and thus was used to estimate the total uncertainty in the experimental measurements.

As discussed in detail in [8], the DOE technique segregates sources of uncertainties into three classes; random uncertainty, flowfield non-uniformity uncertainty, and model and instrumentation uncertainty. Random uncertainty combines uncertainty sources that are due to any type of variability in the operation of the wind tunnel system, assembly and positioning of the model in the test section, and any procedures related to run-time instrumentation calibration procedures. Random uncertainty could also be referred to as end-to-end uncertainty or replicate uncertainty, as long as it is understood that all types of repeatability of the measurements are included. Some examples of replicate run pairs are: replicate runs during a given pitch sweep of the model, as well as replicates separated by several days, replicates after the wind tunnel model has been disassembled and re-assembled, and replicates after the wind tunnel model was positioned at nominally the same location and orientation in the test section. Flowfield non-uniformity uncertainty is the uncertainty in a measured quantity that is due to any type of deviation in uniformity of the flow field in the test section of the wind tunnel. It has been long recognized that flowfield non-uniformity (or flowfield quality) is a significant contributor to uncertainty in wind tunnel measurements, but there has been only limited success in quantifying this contributor. Model and instrumentation uncertainty is uncertainty that is due to (a) imperfections or asymmetries in the wind tunnel model, and (b) sensorto-sensor variabilities in each electronically-scanned pressure (ESP) transducer module and variabilities between modules, their connecting tubing, and the associated orifice on the surface of the model. Details are given in Section IV as to how each of these uncertainties is computed using multiple measurements of the surface pressures.

\section{Experimental Method}

\section{A. Facility}

The NASA LaRC UPWT is a closed-circuit continuous flow pressure tunnel with two test sections that nominally measure $4 \times 4$ feet in cross section and 7 feet in length [26]. The facility is powered by a 100,000horsepower drive motor connected to a series of six centrifugal compressors that are used in specific combinations to provide flow through either of the two test sections, depending on the Mach number. Auxiliary equipment includes an air-drying system, vacuum pumps for evacuation, and a cooling system for regulating airflow temperatures. Stagnation pressures can be varied to a maximum of 50 psia in Test Section 1 and 100 psia in Test Section 2, and the stagnation temperature can be regulated from $560^{\circ} \mathrm{R}$ to $635^{\circ} \mathrm{R}$ for typical operations. An asymmetric sliding-block nozzle in each leg of the facility provides continuous Mach number variation from 1.50 to 2.86 in Test Section 1 and from 2.30 to 4.63 in Test Section 2. A schematic of the nozzle and test section for Test Section 2 is shown in Figure 1. An adjustable second minimum is located aft of each test section to control backpressure and stabilize the normal shock position downstream of the test section.

Both test sections contain identical model support systems that allow independent pitch, yaw, and roll motions as well as forward/aft travel and left/right traverse within the test section. The primary mechanism is a

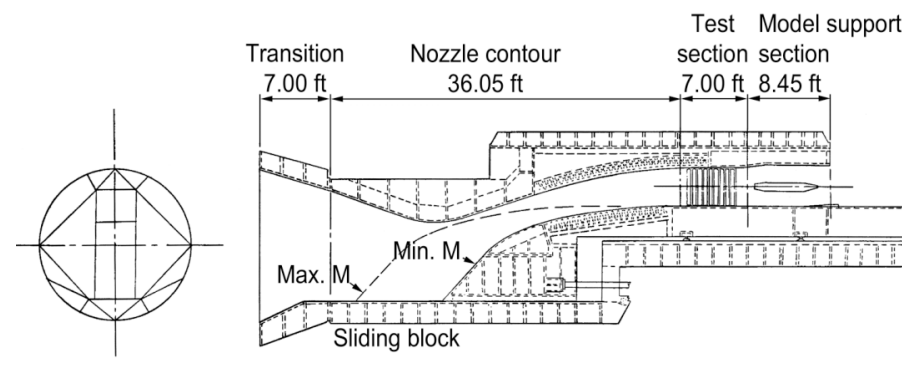

Figure 1. UPWT Test Section 2 nozzle block and test chamber. 
horizontal wall-mounted strut that can be remotely driven a total of 36.25 inches in the axial direction. A sting support attached to the strut allows traverse and yaw movements of \pm 20 inches and $\pm 14^{\circ}$, respectively, while a pitch mechanism located forward of the sting support allows pitch angles from $-12^{\circ}$ to $+20^{\circ}$. Roll motions up to $310^{\circ}$ are provided by a roll mechanism located just upstream of the pitch sector. A diagram of the model support system, including the tunnel coordinate system, is given in Figure 2.

A recently-upgraded high-pressure air system provides propulsion simulation capability for Test Section 2 of UPWT. The system consists of a digital control valve (DCV) that regulates air from the main 5000-psia bottlefield and provides control of pressure, temperature, and mass flow rate to userspecified values and tolerances. Pressure can be controlled from 50-3800 psia, with control accuracies of better than $\pm 2 \%$ from $50-250$ psia and $\pm 1 \%$ from $250-3800$ psia, while temperature is regulated to better than $\pm 5^{\circ} \mathrm{F}$ from ambient to $275^{\circ} \mathrm{F}$. Over these conditions, mass flow is controlled from $0.02-30 \mathrm{lb}_{\mathrm{m}} / \mathrm{sec}$.

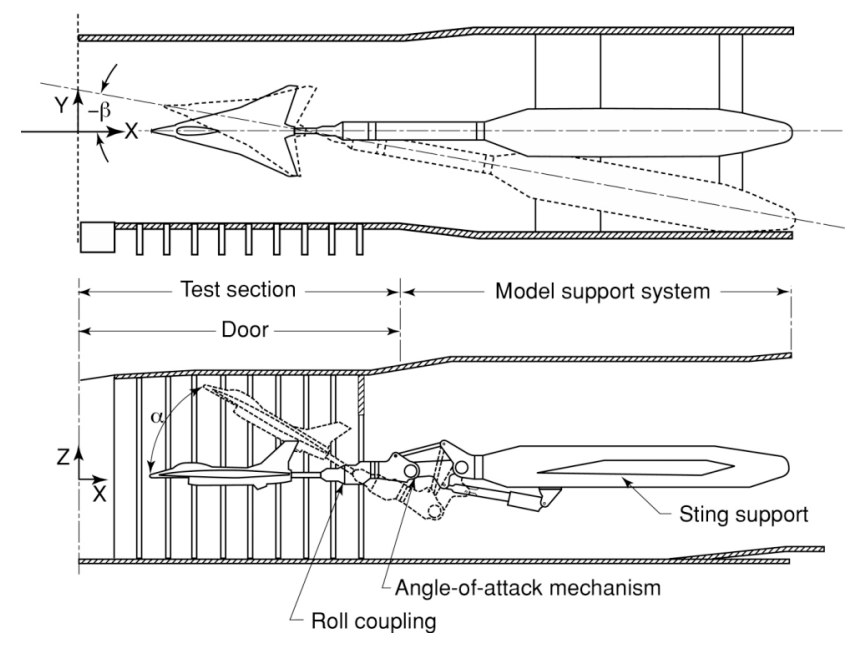

Figure 2. UPWT Test Section 2 model support system.

\section{B. Test Article}

The SRP wind tunnel model measured 5 inches in diameter and 10.556 inches in overall length. The model was comprised of a heavily-instrumented 70-degree sphere-cone forebody with four locations for interchangeable nozzles or flush plug inserts, followed by a cylindrical aftbody, as illustrated in Figure 3. High-pressure air was supplied to the model through a port in the support sting that fed a constant-diameter internal plenum connected to each nozzle via a four-fingered manifold, as shown in Figure 4. One nozzle was located on the model centerline while the other three were centered on the forebody half-radius and spaced $120^{\circ}$ apart. The nozzles were designed with a 4:1 area ratio and a 0.5 -inch exit diameter that yielded an exit Mach number of 2.94 using high-pressure air. In place of the nozzles, plugs could be inserted that fit flush with the forebody to provide the baseline, smooth OML configuration. The aftbody was 9.55 inches in length and consisted of two removeable, thin-walled half cylinders to cover the model structure and protect the internal instrumentation. Additional information on the model design and construction are given in [7] and [14].

\section{Instrumentation}

The model was instrumented with 167 surface pressure ports connected via 0.040 -inch inside-diameter flexible urethane tubing to three Pressure Systems Inc. (PSI) ESP transducer modules located inside the model. The modules were mounted to a thermoplastic resin block that wrapped partway around the sting and insulated the modules from the elevated plenum temperatures. Two 64-channel modules $(0-5 \pm 0.005$ psid) were used to measure 118 forebody ports and 4 aftbody ports. A 48-channel $(0-2.5 \pm 0.003$ psid $)$

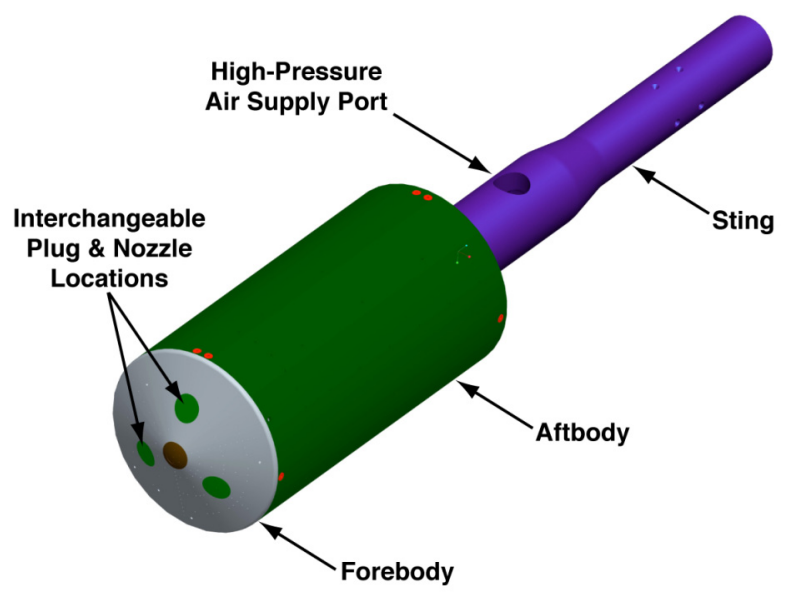

Figure 3. SRP model assembly. module was used to measure pressures for the remaining 45 ports on the aftbody. A diagram of the surface pressure instrumentation layout is shown in Figure 5. Note that the axes origin is located at the virtual nose of a sharp 70degree cone. All three ESP modules were referenced to a hard vacuum to provide absolute pressure measurements. Three separate pressures were independently supplied by Ruska Model 6211-801 pressure gages (0-38 \pm 0.004 psia) to transducers on each ESP module and were monitored to check for drift in the pressure measurements. In-situ calibrations were performed on each ESP module using the system Model 8432-15A pressure calibration unit (PCU, $0-15 \pm 0.003$ psia) when drift exceeded 0.0175 psi. 
Additional instrumentation included seven 0.0625 -inch-diameter Kulite XCS-062-5A pressure transducers (0-5 \pm $0.013 \mathrm{psia}$ ) that were mounted flush to the model forebody surface with adhesive potting material and used to measure fluctuating surface pressures. The locations of the Kulites are shown as the solid symbols in Figure 5. Two additional Kulite transducers were mounted in the model aft shell but were damaged during model assembly. Output signals from the Kulite gages were split to both the standard and high-speed data acquisition systems to provide simultaneous time-averaged and unsteady pressure measurements, respectively.

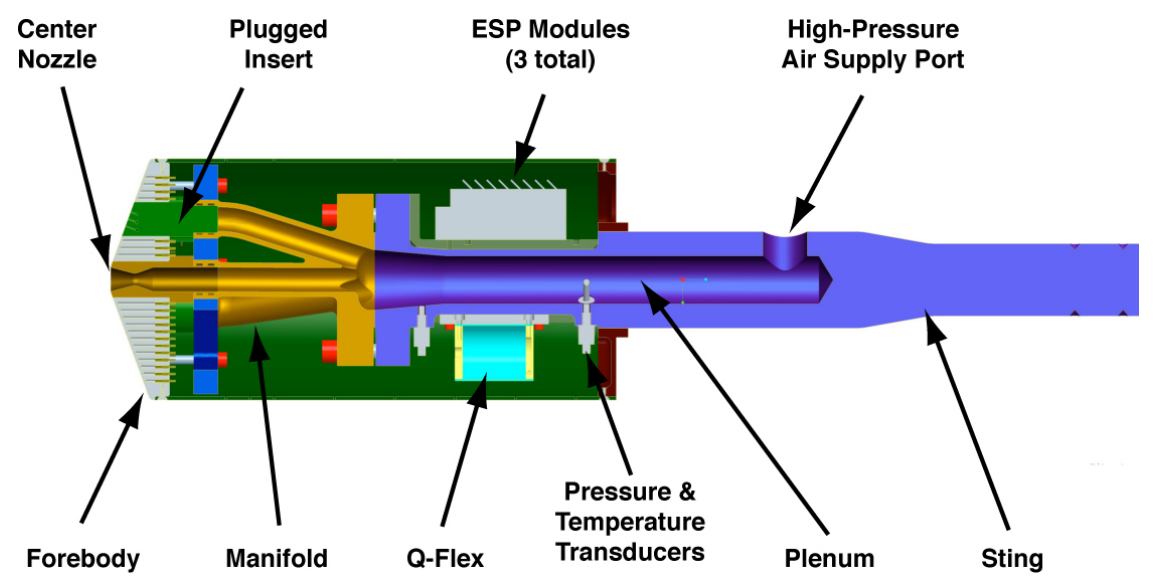

Figure 4. Section view of SRP model.

Pressures were also measured inside the model at different locations along the high-pressure airflow path with up to four Kulite XT-190-2000A pressure transducers (0-2000 \pm 2 psia). Two transducers were located at different stations in the nozzle-flow plenum inside the model, with the gages mounted flush to the plenum inner surface. The other two pressure transducers were mounted to the center nozzle and the forebody half-radius nozzle at $\theta=0^{\circ}$, respectively (see Figure 5). The transducers were connected to interior surface ports located 0.417 inches upstream of the nozzle inlets, as illustrated in Figure 6. Plenum temperatures were measured using a 0.236-in diameter Omega RTD-NPT-72-A platinum resistance temperature detector (RTD) probe $\left(132-910 \pm 1^{\circ} \mathrm{R}\right)$ that extended 0.5 inches from the plenum wall into the high-pressure airflow. Additionally, each of the two instrumented nozzles contained a Type $\mathrm{K}$ thermocouple $\left(132-2742 \pm 4^{\circ} \mathrm{R}\right)$ mounted flush to the inside surface and opposite of the plenum pressure port.


Figure 5. Surface pressure instrumentation layout and model coordinate system. 
A NASA Langley-built Q-Flex accelerometer was mounted inside the model and used to directly measure model pitch angle during the test. The device was calibrated in place as a function of pitch and roll angles using a multi-axis Langley Angle Measurement System (AMS) installed on the model during setup. The resultant angular calibration accuracy was approximately $\pm 0.01^{\circ}$.

Eight Type K thermocouples $\left(132-2742 \pm 4^{\circ} \mathrm{R}\right)$ were installed to monitor the thermal environment inside the model during the test. A thermocouple was mounted between the thermoplastic resin block and each ESP module as well as the accelerometer. The remaining four thermocouples were mounted to the inside surface of the aft shell at approximately half the model length and every 90 degrees around its circumference. The temperatures were monitored in real-time during the test to ensure that the interior model temperature did not exceed the ESP module temperature limit of $180^{\circ} \mathrm{F}$. The average ESP temperature for jet-on runs was approximately $145^{\circ} \mathrm{F}$ with a maximum of around $175^{\circ} \mathrm{F}$.

A calibrated Flow-Dyne Engineering subsonic venturi flow meter with 1.503-inch-diameter inlet and 0.695-inchdiameter throat was installed in the high-pressure air line just outside the test section and used to measure nozzle mass flow rate. The venturi inlet pressure was measured using a Druck PDCR 4060 pressure transducer $(0-3000 \pm$ $2.4 \mathrm{psia}$ ), while the inlet temperature was measured using a 0.25 -inch-diameter Type $\mathrm{T}$ shielded thermocouple probe $\left(132-1122 \pm 2^{\circ} \mathrm{R}\right)$. Pressure drop across the venturi throat was measured with a Bell \& Howell Model 4-351-0004 differential pressure transducer $(0-100 \pm 0.05 \mathrm{psid})$. Mass flow rate uncertainty is estimated to be approximately $\pm 0.07 \mathrm{lb} / \mathrm{sec}$.

The ESP pressure ports and associated pressure tubing were manually checked following each model change to determine if any ports were leaking or if the tubing was pinched or plugged. A small vacuum pump connected to a length of 0.25 -inch-diameter flexible tubing was used to pull a vacuum on the model surface over top of each pressure orifice at a time. Once the vacuum was

Table 1. Faulty pressure ports for baseline configuration

\begin{tabular}{|c|c|c|l|}
\hline Run & $\begin{array}{c}\text { \# Bad } \\
\text { Ports }\end{array}$ & $\begin{array}{c}\text { \% Bad } \\
\text { Ports }\end{array}$ & \multicolumn{1}{|c|}{ Bad Port ID } \\
\hline $13-123$ & 14 & 8.4 & $\begin{array}{l}1,16,24,35,44,46,49,50,56, \\
57,86,97,119,154\end{array}$ \\
\hline $271-283$ & 11 & 6.6 & $\begin{array}{l}2,21,24,26,44,46,51,116, \\
144,170,171\end{array}$ \\
\hline
\end{tabular}
established, a valve in the flexible line was closed to isolate the port, while the response of the individual ESP transducer was monitored for change. A rapid rise in pressure indicated a leak somewhere between the orifice and the ESP module, while a port that was slow to pull to a vacuum or did not respond at all, signified that the pressure tubing was pinched or plugged to some degree. A record was kept of each tubing check, and the faulty pressure ports were assigned pressure and pressure coefficient values of -9999 in the data reduction so that the data from these suspect ports could not be used. The leak checks were also used to verify the instrumentation channel assignments for each pressure port. A list of the faulty pressure ports for the baseline SRP configuration is given in Table 1.

\section{Uncertainty Analysis}

Because one of the important goals of the experiment was to rigorously estimate random and systematic experimental uncertainties with the DOE technique, the design of the test matrix was critically important. The various components of experimental uncertainty were quantified from measurements only on the baseline, smooth OML configuration to minimize or eliminate unsteady jet-on flow effects that could otherwise mask or skew the uncertainty estimates. The test matrix for the baseline configuration, shown in Table 2, featured replicate runs at each Mach number, along with runs performed at different axial and/or lateral positions in the test section. For each run, the angle of attack was set at nominal angles of $-7.8,-4,0,4,8,12,16,20,0^{\circ}$, with the points set in the order shown. The uncertainty for the pitch sector in the model support system was $\pm 0.016^{\circ}$ at a $95 \%$ confidence level, as determine from a calibration using the AMS.

Data were acquired at freestream Mach numbers of 2.4, 3.5, and 4.6 for the mean-value conditions given in Table 3. The variability in the test conditions is due to variations in setting and controlling the tunnel operating 
conditions as well as the nozzle block position. Note that the data show no variation in freestream Mach number. This is because the Mach number is strictly a calibrated function of the nozzle block position at a given nominal unit Reynolds number. During facility operations, the nozzle block is moved to the same position as read on the linear potentiometer display in the control room. Given the change in Mach number per unit of axial nozzle block displacement [26] and the uncertainty of the linear potentiometer ( \pm 0.003 inches), the Mach number repeatability due to nozzle block movement is less than 0.0003. From [26], the variation in Mach number from the test-sectionaverage value can be as high as \pm 0.025 over the range of model locations tested - much greater than any error due to nozzle block positioning.

No flow angle corrections were made in setting the pitch angles, except inadvertently for Run 13-14, where the historical calibration flow angle value was used. These two runs were subsequently reprocessed without the flow angle correction, resulting in angle set point differences of approximately $-0.25^{\circ}$ as compared to the remainder of the runs. At each test section location, runs were made at nominal roll angles of $0,60,120$, and $180^{\circ}$. The accuracy of the model support system roll sector is $\pm 0.026^{\circ}$ at a $95 \%$ confidence level.

Table 2. Test matrix for SRP baseline configuration.

$$
\text { (a) } \mathrm{M}_{\infty}=\mathbf{2 . 4}
$$

\begin{tabular}{|c|c|c|c|c|c|c|c|}
\hline \multirow{2}{*}{$X$, in } & \multirow{2}{*}{$Y$, in } & \multirow{2}{*}{$\alpha_{\mathrm{T}}, \operatorname{deg}$} & \multicolumn{4}{|c|}{$\phi, \operatorname{deg}$} & \\
\hline & & & 0 & 60 & 120 & 180 & \\
\hline \multirow[t]{2}{*}{25} & $\begin{array}{l}0 \\
8\end{array}$ & \multirow{7}{*}{$\mathrm{A} 1$} & $\begin{array}{c}13,16,33 \\
34\end{array}$ & $\begin{array}{c}14,17,32 \\
35\end{array}$ & $\begin{array}{c}18,31 \\
36\end{array}$ & $\begin{array}{c}19,30 \\
37\end{array}$ & \multirow{7}{*}{$\begin{array}{l}\overline{\mathbf{D}} \\
\bar{\Xi} \\
\bar{z} \\
\bar{\Xi}\end{array}$} \\
\hline & -8 & & - & - & - & - & \\
\hline \multirow{3}{*}{40} & 0 & & $20,24,271$ & $21,25,272$ & 22,273 & 23,274 & \\
\hline & 8 & & 41 & 40 & 39 & 38 & \\
\hline & -8 & & $\frac{42}{26}$ & $\frac{43}{27}$ & $\frac{44}{28}$ & 45 & \\
\hline \multirow{2}{*}{50} & 0 & & 26 & 27 & 28 & 29 & \\
\hline & $\begin{array}{c}8 \\
-8\end{array}$ & & $\overline{49}$ & $\overline{48}$ & $\overline{47}$ & $\overline{46}$ & \\
\hline
\end{tabular}

(b) $\mathbf{M}_{\infty}=3.5$

\begin{tabular}{|c|c|c|c|c|c|c|c|}
\hline \multirow{2}{*}{$X$, in } & \multirow{2}{*}{$Y$, in } & \multirow{2}{*}{$\alpha_{\mathrm{T}}, \operatorname{deg}$} & \multicolumn{4}{|c|}{$\phi$, deg } & \\
\hline & & & 0 & 60 & 120 & 180 & \\
\hline \multirow{3}{*}{25} & 0 & \multirow{9}{*}{ A1 } & 57 & 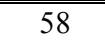 & $\overline{59}$ & $\overline{60}$ & \multirow{9}{*}{ 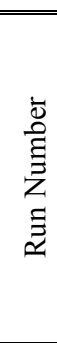 } \\
\hline & 8 & & - & - & - & - & \\
\hline & -8 & & 65 & 67 & 68 & 69 & \\
\hline \multirow{3}{*}{40} & 0 & & 56,279 & 55,278 & 54,277 & 53,276 & \\
\hline & 8 & & 76 & 77 & 78 & 79 & \\
\hline & -8 & & 75 & 74 & 73 & 70 & \\
\hline \multirow{3}{*}{50} & 0 & & - & 50 & 51 & 52 & \\
\hline & 8 & & 83 & 82 & 81 & 80 & \\
\hline & -8 & & - & . & . & - & \\
\hline
\end{tabular}

(c) $M_{\infty}=4.6$

\begin{tabular}{|c|c|c|c|c|c|c|c|}
\hline \multirow{2}{*}{$X$, in } & \multirow{2}{*}{$\mathrm{Y}$, in } & \multirow{2}{*}{$\alpha_{\mathrm{T}}, \operatorname{deg}$} & $\phi, \operatorname{deg}$ & & & & \\
\hline & & & 0 & 60 & 120 & 180 & \\
\hline \multirow{3}{*}{25} & 0 & \multirow{9}{*}{ A1 } & 104 & 105 & 106 & 107 & \multirow{9}{*}{ 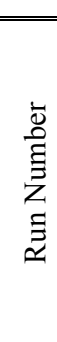 } \\
\hline & 8 & & - & - & - & - & \\
\hline & -8 & & 120 & 121 & 122 & 123 & \\
\hline \multirow{3}{*}{40} & 0 & & 111,280 & 110,281 & 109,282 & 108,283 & \\
\hline & 8 & & - & - & - & - & \\
\hline & -8 & & - & - & - & - & \\
\hline \multirow{3}{*}{50} & 0 & & 112 & 113 & 114 & 115 & \\
\hline & 8 & & 119 & 118 & 117 & 116 & \\
\hline & -8 & & . & 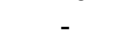 & . & 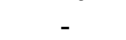 & \\
\hline
\end{tabular}

A1 angle of attack schedule: $-7.8,-4,0,4,8,12,16,20,0^{\circ}$ 
Table 3. Test conditions for SRP baseline configuration.

\begin{tabular}{ccccccc}
\hline \hline \multirow{2}{*}{$\begin{array}{c}\text { Flow } \\
\text { Parameter }\end{array}$} & \multicolumn{9}{c}{ Mach Number } \\
& Mean & & \multicolumn{9}{c}{3.5} & Mean & $\sigma$ & Mean & $\sigma$ \\
\hline $\mathrm{M}_{\infty}$ & 2.4 & 0 & 3.5 & 0 & 4.6 & 0 \\
$\mathrm{P}_{\mathrm{T}}, \mathrm{psfa}$ & 777.85 & \pm 0.585 & 1386.62 & \pm 1.085 & 3657.84 & \pm 0.839 \\
$\mathrm{~T}_{\mathrm{T}},{ }^{\circ} \mathrm{R}$ & 594.81 & \pm 0.478 & 594.68 & \pm 0.543 & 609.91 & \pm 0.340 \\
$\mathrm{P}_{\infty}, \mathrm{psfa}$ & 53.20 & \pm 0.040 & 18.18 & \pm 0.014 & 11.17 & \pm 0.003 \\
$\mathrm{q}_{\infty}, \mathrm{psfa}$ & 214.52 & \pm 0.161 & 155.89 & \pm 0.122 & 165.39 & \pm 0.038 \\
$\mathrm{Re}_{\infty}, 1 / \mathrm{ft}$ & 998,983 & \pm 1274 & 999,654 & \pm 1497 & $1,498,914$ & \pm 1410 \\
\hline \hline
\end{tabular}

\section{A. Data Interpolation}

The pressure measurement data files were first interpolated to common angles of attack so that replicate measurements would be compared for the same angles of attack. If this was not done, the DOE technique would improperly ascribe pressure measurement uncertainty to the inability of the model positioning system to attain the same angle of attach for each run. A custom program written in the Data Engineering Scripting Language (DESL) [27] software was used to interpolate the data to total angle of attack values of $-7.8,-4,0,4,7.8,12,16$, and $19.9^{\circ}$. The interpolation was accomplished by using an intrinsic routine that locally fits a $3^{\text {rd }}$-degree polynomial to the nearest four data points around each chosen value. To preserve the two independent $\alpha_{\mathrm{T}}=0^{\circ}$ points in each run, the interpolation was done twice, using only one of the $\alpha_{T}=0^{\circ}$ points per calculation. The second interpolated $\alpha_{T}=0^{\circ}$ point was added to the set of points from the first interpolation to form the complete interpolated data file. The interpolation angles were chosen to avoid extrapolation of data in any of the runs. The $\alpha_{T}=+7.8^{\circ}$ value was chosen to mirror its negative counterpart for use in the calculations of uncertainty associated with flowfield non-uniformity effects. Samplings of the interpolated data were plotted for comparison with the corresponding original data, and in all instances the agreement was excellent. The average model pitch angle settings are given in Table 4, along with summary statistics.

Data were not interpolated based on roll angle for two reasons. First, the sparseness of the data (only four roll angles) and the large 60-degree magnitude of the increments could cause large interpolation errors. It was felt that the potential numerical error in such interpolations could affect the calculated uncertainties as much or greater than small roll angle differences in the data. Second, the variability in the setting of roll angle was relatively small, as can be seen in Table 4, especially for roll angles of $\phi=0^{\circ}$ and $180^{\circ}$.

Table 4. Summary statistics for SRP model pitch and roll angles.

\begin{tabular}{cccccccc}
\hline \hline \multicolumn{2}{c}{ Angle, deg } & $\mathrm{N}$ & Min & Median & Max & Mean & $\sigma$ \\
\hline & -7.8 & 110 & -7.972 & -7.871 & -7.635 & -7.873 & 0.034 \\
& -4 & 113 & -4.240 & -4.041 & -3.715 & -4.039 & 0.043 \\
\multirow{6}{*}{ PITCH } & 0 & 235 & -0.236 & -0.012 & 0.284 & -0.008 & 0.049 \\
& 4 & 112 & 3.762 & 3.967 & 4.032 & 3.966 & 0.029 \\
& 8 & 112 & 7.731 & 7.868 & 7.939 & 7.868 & 0.021 \\
& 12 & 111 & 11.643 & 11.968 & 12.034 & 11.963 & 0.040 \\
& 16 & 111 & 15.476 & 15.966 & 16.031 & 15.955 & 0.063 \\
ROLL & 111 & 19.202 & 19.962 & 19.988 & 19.944 & 0.106 \\
& 20 & 272 & -0.069 & -0.009 & 0.051 & -0.007 & 0.039 \\
& 120 & 264 & 58.355 & 59.800 & 60.082 & 59.596 & 0.507 \\
\hline \hline
\end{tabular}




\section{B. Calculation of Residuals}

The components of uncertainty were estimated from the statistical analysis of residuals determined through the comparisons of measurements from certain parings of runs and pressure ports. For instance, a comparison of replicate runs at the same Mach number, test section location, and model angular orientation yields information about the random error component of uncertainty. Conversely, a comparison of runs at the same model orientation but different locations in the test section provides information about uncertainty due to flowfield non-uniformity. Similarly, a comparison of different pressure port measurements for the same location in the test section, and the same location in the blunt body flowfield, would provide information about uncertainty due to model geometry/instrumentation asymmetries. The test matrix given in Table 2 was used to identify pairs of runs from which the residuals were calculated for each of the three components of uncertainties discussed above. An example set of run pairings for determining the random uncertainty of the baseline configuration at $\mathrm{M}_{\infty}=4.6$ is shown in Table 5, while a complete listing of all the run pairings for all of the uncertainty components is given in [15].

Table 5. Run pairings for random uncertainty for the baseline configuration at Mach 4.6.

\begin{tabular}{|c|c|c|c|c|}
\hline $\begin{array}{l}\text { Run Pair } \\
\text { Number }\end{array}$ & Run Pair & $\begin{array}{l}\text { Number of } \\
\text { Comparisons }\end{array}$ & $\begin{array}{c}\text { Approximate \# of } \\
\text { Pressure Port } \\
\text { Comparisons } \\
\end{array}$ & $\begin{array}{c}\text { Type of } \\
\text { Comparison }\end{array}$ \\
\hline 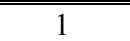 & 111,280 & 11 & 1650 & Long Term \\
\hline 2 & 111,111 & 1 & 150 & Short Term \\
\hline 3 & 280,280 & 1 & 150 & Short Term \\
\hline 4 & 104,104 & 1 & 150 & Short Term \\
\hline 5 & 120,120 & 1 & 150 & Short Term \\
\hline 6 & 112,112 & 1 & 150 & Short Term \\
\hline 7 & 119,119 & 1 & 150 & Short Term \\
\hline 8 & 110,281 & 11 & 1650 & Long Term \\
\hline 9 & 110,110 & 1 & 150 & Short Term \\
\hline 10 & 281,281 & 1 & 150 & Short Term \\
\hline 11 & 105,105 & 1 & 150 & Short Term \\
\hline 12 & 121,121 & 1 & 150 & Short Term \\
\hline 13 & 113,113 & 1 & 150 & Short Term \\
\hline 14 & 118,118 & 1 & 150 & Short Term \\
\hline 15 & 109,282 & 11 & 1650 & Long Term \\
\hline 16 & 109,109 & 1 & 150 & Short Term \\
\hline 17 & 282,282 & 1 & 150 & Short Term \\
\hline 18 & 106,106 & 1 & 150 & Short Term \\
\hline 19 & 122,122 & 1 & 150 & Short Term \\
\hline 20 & 114,114 & 1 & 150 & Short Term \\
\hline 21 & 117,117 & 1 & 150 & Short Term \\
\hline 22 & 108,283 & 11 & 1650 & Long Term \\
\hline 23 & 108,108 & 1 & 150 & Short Term \\
\hline 24 & 283,283 & 1 & 150 & Short Term \\
\hline 25 & 107,107 & 1 & 150 & Short Term \\
\hline 26 & 123,123 & 1 & 150 & Short Term \\
\hline 27 & 115,115 & 1 & 150 & Short Term \\
\hline 28 & 116,116 & 1 & 150 & Short Term \\
\hline \multicolumn{2}{|c|}{ Total Number } & 68 & 10,200 & $\begin{array}{l}3600 \text { s.t. } \\
6600 \text { 1.t. }\end{array}$ \\
\hline
\end{tabular}

Given a pair of runs denoted by run numbers $r$ and $s$, the average pressure coefficient of the two runs for port $i$ and angle of attack $j$ is given by

$$
\overline{\left(C_{p_{i}}\right)_{j}^{r, s}}=\frac{1}{2} \delta_{i}^{r, s}\left[\left(C_{p_{i}}\right)_{j}^{r}+\left(C_{p_{i}}\right)_{j}^{s}\right],
$$


where $i=1,2, \ldots, 176$ (and corresponds to the Port ID) and $j=1,2, \ldots, m$. Here, $m$ is the total number of angles of attack considered for comparison, and varies depending on the type of comparison being made. The residual is defined as the absolute value of the difference between the pressure coefficient from one of the runs and the average value, and is computed as

$$
\left(\Delta C_{p_{i}}\right)_{j}^{r, s}=\delta_{i}^{r, s}\left|\left(C_{p_{i}}\right)_{j}^{r}-\overline{\left(C_{p_{i}}\right)_{j}^{r, s}}\right|
$$

In the two equations above, the parameter $\delta_{i}^{r, s}$ denotes the health of the pressure port as determined from leak checks performed during the test after each model change, and is calculated as

$$
\delta_{i}^{r, s}=\delta_{i}^{r} \delta_{i}^{s}
$$

where $\delta_{i}=[0,1]$, for $i=1,2, \ldots, 176$, and a value of 0 denotes a "bad" port. Thus, if a pressure port is faulty for either run, the average and residual pressure coefficient values for that port compute exactly to zero. This was done so that information from leaking, pinched, or plugged pressure ports would not influence the calculated uncertainty estimates. Additionally, in the calculations above, the pressure ports identified as Kulite pressure transducers (Ports 105-111) were treated as faulty ports so that those measurements would not be included with those from the ESP modules.

For each Mach number, the sample variance for each component of uncertainty was computed from the residuals as

$$
\sigma^{2}=\frac{1}{N} \sum_{k=1}^{N}\left[\Delta C_{p}\right]_{k}^{2}
$$

where

$$
N=\sum_{q=1}^{L} \sum_{i=1}^{176}\left[\delta_{i}^{r, s}\right]_{q}
$$

and $L$ is the total number of data records used in the determination of a particular uncertainty component. Note that in the summation above, the faulty pressure ports do not count towards the total, $N$, and thus do not bias the calculated variances.

\section{Random Uncertainty}

The random uncertainty in the pressure measurements stems from a host of sources, such as instrumentation drift and hysteresis, repeatability of the reference pressure and pressure calibration unit (PCU), repeatability of model location and attitude settings, and within-run and between-run variations in flow conditions. Random uncertainty was estimated through the comparisons of pressure measurements for the same ports on the model for replicate runs made at the same Mach number, test section location, and model angular orientation. For a specified pair of replicate runs, the pressure ports on the model are exposed to the same relative flowfield at a given angle of attack, and the differences in pressure between the two runs caused by flowfield non-uniformity and model geometry/instrumentation effects cancel out, leaving only the effect due to random error.

Two different types of replicates were used in the estimation of random uncertainty. The first type was a withinrun replicate of the $\alpha_{T}=0^{\circ}$ points, which were the third and ninth points acquired within a run, respectively. The residuals were computed from these data points using a custom DESL script, and were used to estimate the shortterm repeatability of the data. The elapsed time between acquisition of the two points was approximately 30 seconds. The number of residuals calculated per run pair for the short-term repeatability is $\left(1 \alpha_{\mathrm{T}}\right.$ comparison $) \times$ (167 pressure ports) $=167$ residuals, less those from the faulty pressure ports.

The second type of replicate was a run-to-run replicate, where comparisons are made for corresponding points between the two runs. A total of nine points were obtained for each run - seven at non-zero angles of attack and two at $\alpha_{T}=0^{\circ}$. From the latter, four permutations of comparisons are possible at $\alpha_{T}=0^{\circ}$, yielding a total of 11 angle of attack comparisons per run pair. Thus, for each run pair, the number of calculated residuals is ( $11 \alpha_{\mathrm{T}}$ comparisons $)$ $\times(167$ pressure ports $)=1837$ residuals, less those from faulty pressure ports. The elapsed time between replicate runs ranged from minutes and hours (deemed medium-term repeatability) to days (long-term repeatability). The 
long-term repeatability included runs following a rebuild of the baseline model configuration, thus incorporating variation due to configuration change repeatability into the uncertainty estimates. The long-term repeatability would also include any changes in compressor plant operation and effects of changes in atmospheric conditions on the facility, such as might affect the ability to maintain low humidity levels (i.e. dew point), for example.

The random uncertainty residuals for each Mach number are plotted in Figure 7. Each graph shows the $\mathrm{C}_{\mathrm{p}}$ residuals plotted versus the average $\mathrm{C}_{\mathrm{p}}$ value computed in each measurement comparison, along with histograms to show the distribution along each axis. The residuals are separated into two distinct groups by average $\mathrm{C}_{\mathrm{p}}$; the lower pressures are associated with the aft body while the higher pressures are associated with the forebody. The magnitude of the residuals are given on the lower right side of each graph and appear to be normally distributed with a mean value close to zero and relatively heavy tails. From the histogram plots, the majority of the residuals appear to have values of $\Delta \mathrm{C}_{\mathrm{p}}<$ 0.001. The lengths of the tails of the distributions increase with increasing Mach number, indicating a

Table 6. Summary of random error pressure coefficient uncertainties.

\begin{tabular}{ccccc}
\multicolumn{5}{c}{$\left(\mathbf{a )} \mathbf{M}_{\infty}=\mathbf{2 . 4}\right.$} \\
\hline & $\begin{array}{c}\text { Short } \\
\text { Term }\end{array}$ & $\begin{array}{c}\text { Medium } \\
\text { Term }\end{array}$ & $\begin{array}{c}\text { Long } \\
\text { Term }\end{array}$ & Total \\
\hline \hline $\mathrm{L}$ & 40 & 104 & 66 & 210 \\
$\mathrm{~N}$ & 6128 & 15912 & 9504 & 31544 \\
$\sigma$ & 0.00068 & 0.00109 & 0.00144 & 0.00115 \\
\% Total & 6.8 & 45.9 & 47.3 & 100 \\
Variance & & & & \\
\hline
\end{tabular}

(b) $\mathrm{M}_{\infty}=3.5$

\begin{tabular}{|c|c|c|c|c|}
\hline & $\begin{array}{l}\text { Short } \\
\text { Term } \\
\end{array}$ & $\begin{array}{c}\text { Medium } \\
\text { Term } \\
\end{array}$ & $\begin{array}{l}\text { Long } \\
\text { Term } \\
\end{array}$ & Total \\
\hline L & 31 & \multirow{4}{*}{ N/A } & 44 & 75 \\
\hline $\mathrm{N}$ & 4751 & & 6336 & 11087 \\
\hline$\sigma$ & 0.00052 & & 0.00238 & 0.00183 \\
\hline $\begin{array}{c}\% \text { Total } \\
\text { Variance }\end{array}$ & 3.4 & & 96.6 & 100 \\
\hline \multicolumn{5}{|c|}{ (c) $M_{\infty}=4.6$} \\
\hline & $\begin{array}{l}\text { Short } \\
\text { Term } \\
\end{array}$ & $\begin{array}{c}\text { Medium } \\
\text { Term } \\
\end{array}$ & $\begin{array}{l}\text { Long } \\
\text { Term } \\
\end{array}$ & Total \\
\hline $\mathrm{L}$ & 24 & \multirow{4}{*}{ N/A } & 44 & 68 \\
\hline $\mathrm{N}$ & 3680 & & 6336 & 10016 \\
\hline$\sigma$ & 0.00089 & & 0.00363 & 0.00294 \\
\hline $\begin{array}{l}\% \text { Total } \\
\text { Variance }\end{array}$ & 3.4 & & 96.6 & 100 \\
\hline
\end{tabular}

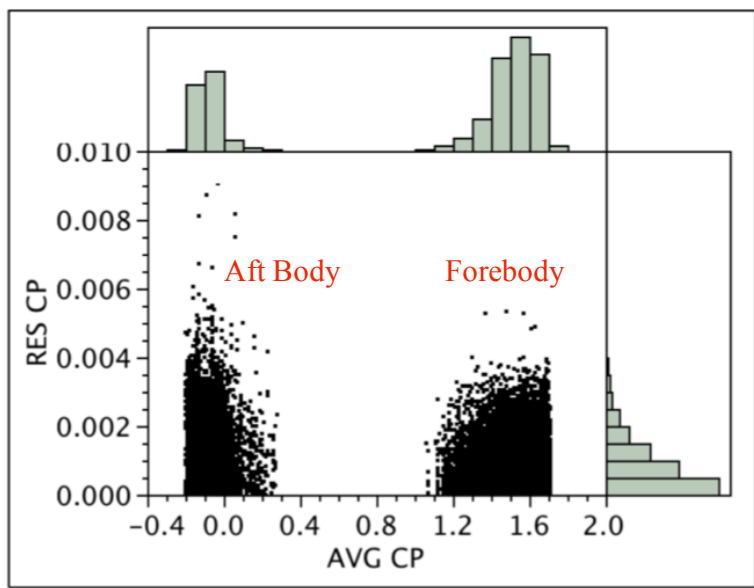

(a) $M_{\infty}=2.4$

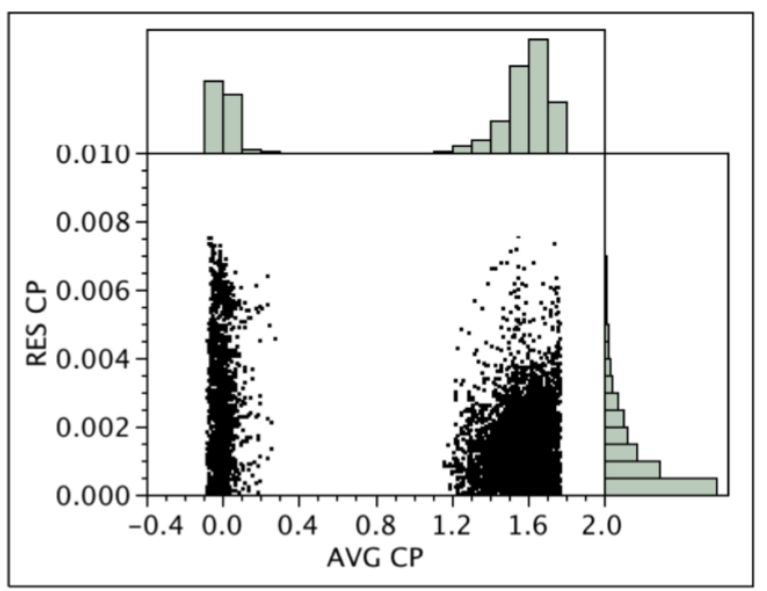

(b) $\mathrm{M}_{\infty}=3.5$

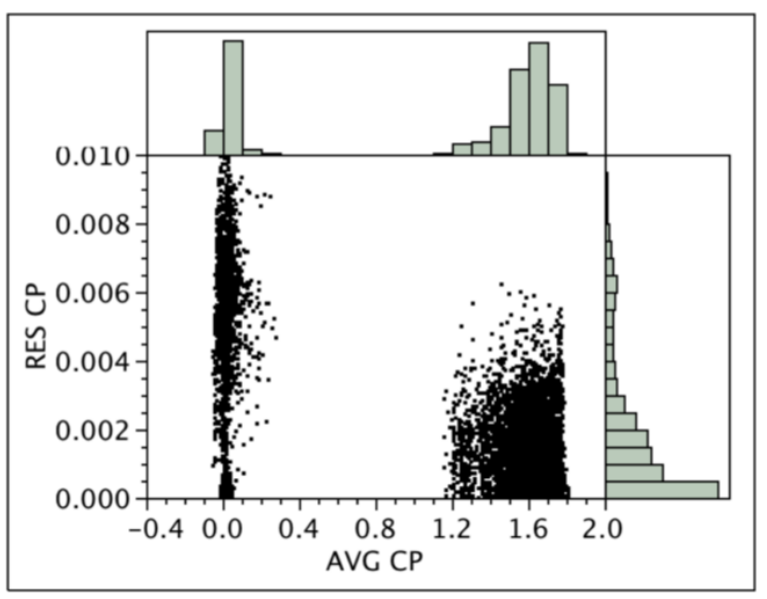

(c) $\mathrm{M}_{\infty}=4.6$

Figure 7. Distribution of pressure coefficient residuals for random uncertainty.

* Because the residuals are absolute-valued quantities, the distribution will appear as only one half of a normal distribution. 
greater frequency of larger-valued residuals at the higher Mach numbers.

The calculated random uncertainties for each Mach number are given in Table 6 and plotted in Figure 8. Here, the uncertainties are broken down into their respective short, medium, and long-term components. Note that no medium-term replicates were available at Mach 3.5 and 4.6. The general trend is for the random uncertainty to increase both with Mach number and with time between replicates. The short-term repeatability contributes very little to the overall random uncertainty at each Mach number.

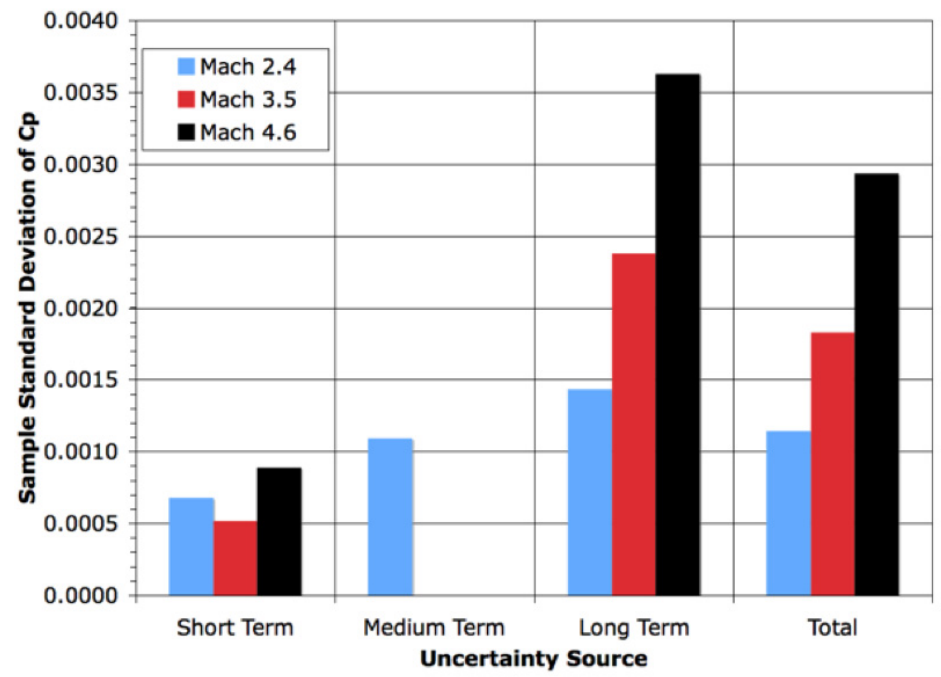

Figure 8. Random uncertainties for the SRP baseline configuration.

\section{Flowfield Non-Uniformity Uncertainty}

The uncertainty associated with flowfield non-uniformity can be caused by several factors. The first is spatial variation of the freestream flow itself within the test section, stemming from asymmetries and deviations in the nozzle wall contours, inaccurate positioning of the nozzle block, variations in freestream turbulence levels, total temperature variations due to inadequate mixing in the settling chamber, Mach waves/shocks propagating through the test section from wall surface protuberances, and a non-optimal nozzle contour (for the particular Reynolds number being used) that does not facilitate characteristic wave cancellation. These factors can produce spatial differences in pressure, temperature, density, velocity, enthalpy, as well as flow streamline angle.

Another major cause is random and bias uncertainty in the angular alignment of the model, generally due to inaccuracies in the various instruments used to establish the model angle, such as bubble levels, inclinometers, or accelerometers placed on or within the model, and encoders or accelerometers typically used in the pitch, yaw, and roll sectors of a model support system. Additional bias can be produced by errors in the alignment (or knowledge of the alignment) of a model level plate or reference surface with the model coordinate system. All these potential uncertainties reveal themselves as flow angularity effects.

To ascertain the uncertainty due to flowfield non-uniformity, runs were made with the model at three different axial $(\mathrm{X})$ and lateral $(\mathrm{Y})$ locations in the test section, for a total of nine possible positions covering an area of $25 \mathrm{x} 16$ inches. The model nose positions in the X-Y plane at zero angle of attack are shown in Figure 9 as the intersections of the grid lines. The test section coordinate system, with the origin just upstream of the test section, is also shown. The computer-controlled model support system was used to move the horizontal strut fore and aft and from side to side while the tunnel was operating. While the system was capable of translating the model further downstream, the furthest aft model position was chosen to keep the model within the schlieren field of view at all angles of attack. Likewise, the side-to-side movement was limited to \pm 8 inches to avoid shock reflections back onto the model from close proximity with the sidewall. The pitch angle of the model provided a total vertical Z-movement of the model nose of approximately 12 inches throughout the angle of attack range tested.

The flowfield non-uniformity uncertainty was obtained from two types of comparisons of runs at different locations in the test section. For the first type, measurements made at the same Mach number and angles of attack, but at different test section locations (X, Y coordinates), are compared for the same pressure ports. Only the first eight points in a run are considered; the second $\alpha_{T}=0^{\circ}$ points are not compared to avoid oversampling that particular angle and giving inappropriate weight to the associated residuals. Thus, for each run pair, the number of 
calculated residuals is $\left(8 \alpha_{\mathrm{T}}\right.$ comparisons $) \times(167$ pressure ports $)=1336$ residuals, less those from faulty pressure ports.

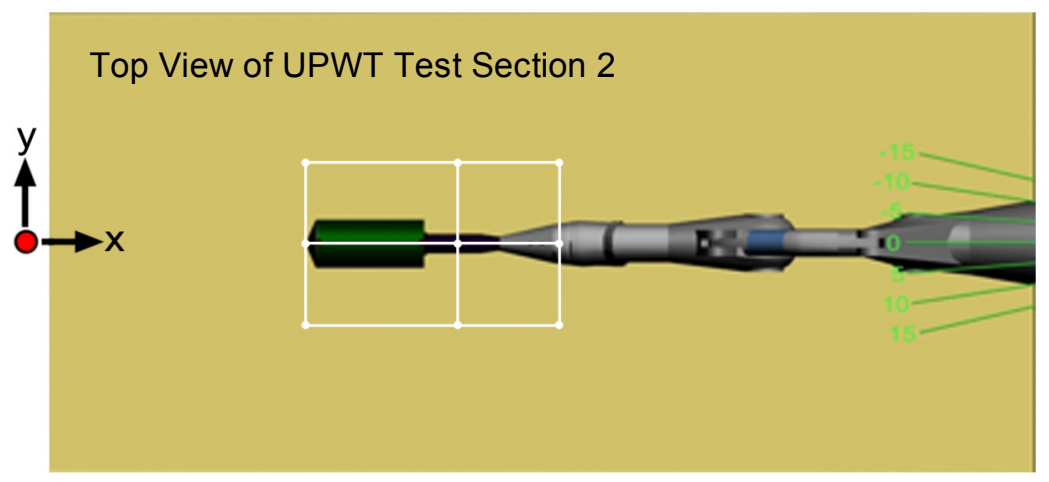

Figure 9. Model nose locations at $\alpha_{T}=0^{\circ}$ during SRP experiment.

The second type of comparison contrasts measurements for the same pressure ports made at positive $\alpha_{\mathrm{T}}$ and a roll angle of $0^{\circ}$ with those at the corresponding negative $\alpha_{\mathrm{T}}$ (same magnitude of angle) and a roll angle of $180^{\circ}$. These comparisons were made for runs at the same or different $X-Y$ locations in the test section, and permit flowfield differences due to different Z-locations in the test section to be captured in the uncertainty estimates. For a pair of runs at different $\mathrm{X}-\mathrm{Y}$ test section locations, comparisons can be made at $\alpha_{\mathrm{T}}= \pm 4^{\circ}$ and $\pm 7.8^{\circ}$, for a total of four permutations. Each comparison involves measurements made at different $\mathrm{X}, \mathrm{Y}, \mathrm{Z}$ locations from one another. For a run pair at the same X-Y test section location, comparisons are made for measurements from one run at $\alpha_{\mathrm{T}}=$ $4^{\circ}$ and $-7.8^{\circ}$ to those from the other run at $\alpha_{T}=+4^{\circ}$ and $+7.8^{\circ}$, respectively, for a total of two comparisons. The contrary comparisons yield the same information on flowfield non-uniformity at that X-Y test section location and are thus omitted to avoid redundant sampling at that location. For each run pair, the number of calculated residuals is $\left(2\right.$ or $4 \alpha_{T}$ comparisons $) \times(167$ pressure ports $)=334$ or 668 residuals, less those from faulty pressure ports.

All measurements contain random uncertainty, so the analysis of the residuals will yield an uncertainty that includes both flowfield non-uniformity and random error effects. Therefore, the random error variance must be subtracted to obtain just the flowfield non-uniformity uncertainty contribution,

$$
\sigma_{\text {flowfield }}=\sqrt{\sigma_{\text {flowfield }+ \text { random }}^{2}-\sigma_{\text {random }}^{2}} .
$$

\section{E. Model Geometry/Instrumentation Uncertainty}

The final type of uncertainty is that due to the model geometry and surface pressure instrumentation. This includes any physical departure of the model surface coordinates from the as-designed geometry, whether due to errors in the model fabrication, damage to the surface, distortion and bending from pressure and temperature loads, or variations in surface roughness that could lead to flowfield asymmetries, such as boundary layer transition. In addition to model geometry imperfections, the pressure measurements are affected by leaks in the pressure tubing, small kinks in the pressure tubing that were not detected in the faulty pressure port checks, pressure orifices that are not flush with the surface or are distorted or damaged in some way, and small biases between transducers in the ESP modules.

The model geometry/instrumentation uncertainty is computed by comparing pressure measurements at different ports on the model, but at the same physical location in the test section and at the same relative location in the vehicle flowfield. By necessity, this requires that the pressure ports used in the comparisons be located in areas of the model that maintain some type of symmetry. The axisymmetry of the SRP model allowed for a relatively large number of pressure port comparisons to compute this uncertainty component. Because these comparisons are made at the same locations in the test section, the flowfield non-uniformity effects cancel out, leaving only the uncertainty due to the model geometry and instrumentation asymmetries in addition to the ever-present random error component.

The test matrix was examined to identify pairs of runs at the same $\mathrm{X}, \mathrm{Y}, \mathrm{Z}$ location in the test section, and at the same angle of attack, but at different roll angles. The instrumentation layout in Figure 5 was examined to determine 
which pressure ports corresponded to one another for roll angle differentials of $\Delta \phi=60^{\circ}, 120^{\circ}$, and $180^{\circ}$. Tables of these corresponding ports were used in the calculation of the residuals via DESL scripts. Because the pressure port layout is not uniformly symmetric on the model, the number of port comparisons for each roll angle differential was not constant. The number of comparisons were 117, 90, and 30 for differential roll angles of $\Delta \phi=60^{\circ}, 120^{\circ}$, and $180^{\circ}$, respectively. The residuals are computed via Eqns. 1-3, with the index $i$ corresponding to the number of comparisons just discussed rather than the port ID, as had been done previously.

Comparisons are made between runs at the seven non-zero angles of attack in addition to the four comparisons available from the permutations of the two $\alpha_{T}=0^{\circ}$ points available in each run, for a total of 11 angle of attack comparisons. For a given run pair, the number of calculated residuals is $\left(11 \alpha_{T}\right.$ comparisons $) \times(30,90$, or 117 pressure ports $)=330,990$, or 1287 residuals, respectively, less those from the faulty pressure ports.

As stated earlier, random uncertainty is present in all measurements; thus the summation of the square of the residuals gives a variance that includes both model geometry/instrumentation uncertainty as well as random error uncertainty. Therefore, the random error variance must be subtracted to obtain only the model geometry/instrumentation uncertainty,

$$
\sigma_{\text {geometry }}=\sqrt{\sigma_{\text {geometry+random }}^{2}-\sigma_{\text {random }}^{2}} .
$$

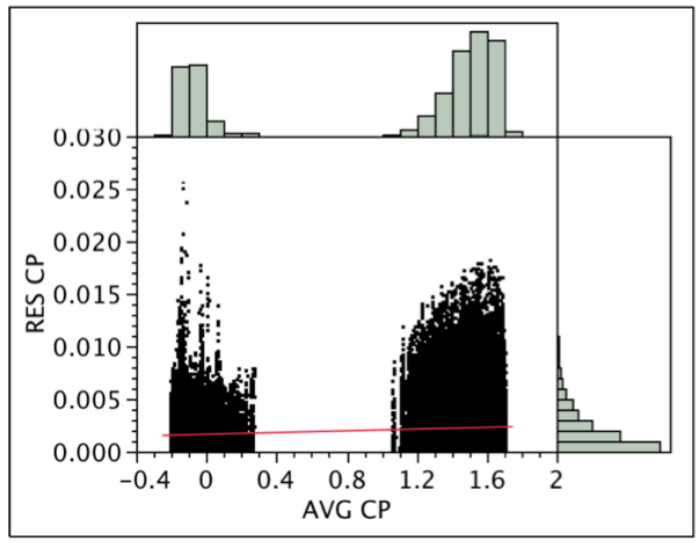

(a) $\mathrm{M}_{\infty}=2.4$

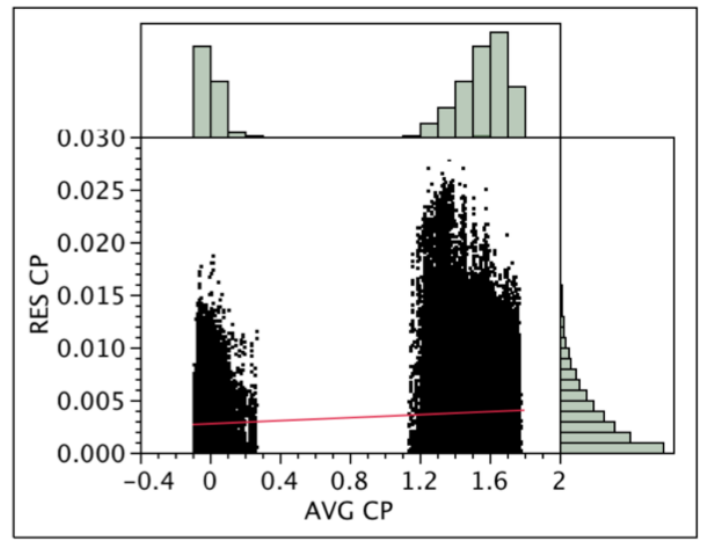

(b) $\mathrm{M}_{\infty}=3.5$

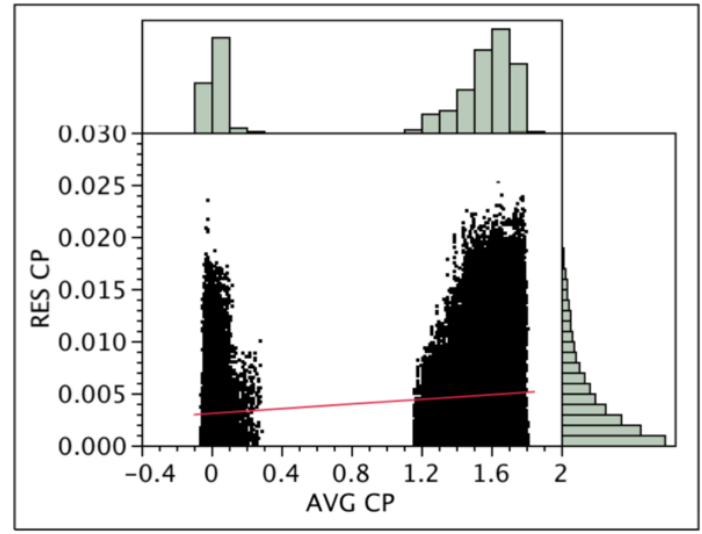

(c) $\mathrm{M}_{\infty}=4.6$

Figure 10. Distribution of pressure coefficient residuals from all uncertainty sources.

\section{F. Total Uncertainty}

The residuals from all three uncertainty sources are plotted in Figure 10 for each Mach number, along with linear trend lines and histograms showing the relative distribution of the averages and residuals. In general, the residuals show similar characteristics to those for the random uncertainties, with the residuals divided into two distinct groups based on whether the measurement was on the forebody or aft body. The magnitude of the residuals appear to be normally distributed with mean values near zero, and the lengths of the tails grow with increasing Mach number. 
The trendlines resulting from linear least-squares fits suggest an overall increase in the magnitude of the residuals with increasing $C_{p}$. However, the values of the quality-of-fit metric $R^{2}$ are quite low, ranging from $R^{2}=$ 0.021 at $\mathrm{M}_{\infty}=2.4$ to $\mathrm{R}^{2}=0.039$ at $\mathrm{M}_{\infty}=4.6$, thus indicating poor fit correlations. This differs considerably from the observations in [10] and [12] (and reported in [8]), where the values of the residuals grew consistently with increasing pressure. One hypothesis is that the differing observations between the two experiments stem from the disparity in the fundamental flow character occurring on the two test articles. The Sandia National Laboratories Joint Computational/Experimental Aerodynamics Program (JCEAP) experiment described in [11-13] utilized a spherically-blunted slender cone at Mach 8 . The JCEAP geometry had relatively large regions of attached flow, and supersonic flow over the majority of the geometry. This contrasts with the blunt SRP model, with large regions of subsonic flow on the forebody, flow expansion and separation at the sharp shoulder, and flow reattachment on the aft body. The sensitivity of the mixed separated and reattached aft body flowfield to random factors and flowfield non-uniformities may result in the large residuals seen at the low values of $\mathrm{C}_{\mathrm{p}}$, i.e., pressures measured on the aft body.

The total uncertainty at each Mach number is computed from the sum of the variances of the individual uncertainty components,

$$
\sigma_{\text {total }}=\sqrt{\sigma_{\text {random }}^{2}+\sigma_{\text {flowfield }}^{2}+\sigma_{\text {geometry }}^{2}} \text {. }
$$

A summary of the pressure coefficient uncertainties from all sources is given in Table 7. By a large margin, the largest source of uncertainty is flowfield non-uniformity, which contributes $71-80 \%$ to the overall variance. This is in general agreement with the results found during the JCEAP experiment, as well as earlier results obtained in supersonic Tunnels A and B at the von Karman Gas Dynamics Facility of the Arnold Engineering and Development Center [10]. A recent study [28] has found a similar result by the ISO/ANSI uncertainty estimation methodology, i.e., the dominant contributor to wind tunnel measurement uncertainty is due to the non-uniform flowfield. The comprehensive study used two different size models in the supersonic wind tunnel of the Japan Aerospace Exploration Agency, as well as positioning the models at different axial and vertical locations in the test section, and using different centers of rotation for force and moment measurements. By comparing the results from each of these experiments they found that they had to introduce correction factors up to a value of 200 for the bias limit term in order to obtain overlap between the estimated uncertainties from each of these experiments. They also found, as would be expected, that the magnitude of the effect of flowfield non-uniformity depends on the magnitude of the flowfield non-uniformity gradient, the size of the wind tunnel model, and the geometry of the model being tested.

Table 7. Summary of pressure coefficient uncertainties.

\begin{tabular}{cccccc}
\hline \multirow{2}{*}{ Mach } & Uncertainty & \# Records, $L$ & \# Residuals, $N$ & $\sigma$ & $\begin{array}{c}\text { \% Total } \\
\text { Variance }\end{array}$ \\
& Source & 210 & 31,544 & 0.00111 & 8 \\
\multirow{4}{*}{2.4} & Random & 830 & 126,108 & 0.00341 & 75 \\
& Flowfield & 786 & 60,990 & 0.00160 & 17 \\
& Geometry & 1826 & 218,642 & 0.00394 & 100 \\
\hline \multirow{3}{*}{3.5} & Total & 75 & 11,087 & 0.00183 & 10 \\
& Random & 780 & 118,332 & 0.00531 & 80 \\
& Flowfield & 528 & 37,720 & 0.00190 & 10 \\
& Geometry & 1383 & 167,139 & 0.00593 & 100 \\
\hline & Total & 68 & 10,016 & 0.00294 & 15 \\
& Random & 410 & 62,010 & 0.00637 & 11 \\
& Flowfield & 320 & 28,392 & 0.00276 & 13 \\
\hline
\end{tabular}

Figure 11 shows the magnitude of each of the component uncertainties as a function of Mach number. All of the uncertainties increase with Mach number, perhaps due to the larger spatial variations in Mach number and flow angularity in the test section at the higher Mach numbers, as documented in [26]. The uncertainties due to random error and model geometry/instrumentation are roughly equivalent to one another in magnitude across the Mach number range, while the uncertainty due to flowfield non-uniformity stands out as the major contributor to the total uncertainty in the experiment. Figure 11 also highlights the inadequacy of basing the uncertainty in an experiment 
solely on replication - a common practice in wind tunnel testing - even when long-term data repeatability is assessed. Depending on the Mach number, the total uncertainty is 2.5 to 4 times the random error uncertainty, largely due to the flowfield non-uniformity uncertainty that was captured in the data through the specific design of this experiment. Thus, the use of just data repeatability as a measure of uncertainty would only result in a gross underestimate of the true variation in the results.

Traditional ISO/ANSI uncertainty analyses often fail to quantify the contributions of flowfield non-uniformity, either through a lack of recognition of its relative importance, or because information about the spatial variations in the facility freestream flow field are incomplete or unavailable to the analyst. Additionally, the model geometry/instrumentation uncertainty would be difficult if not impossible to determine using the ISO/ANSI methodology. An analyst would need information not only about all of the model geometry deviations and imperfections, but also the localized effects that those imperfections would have on the parameters of interest.

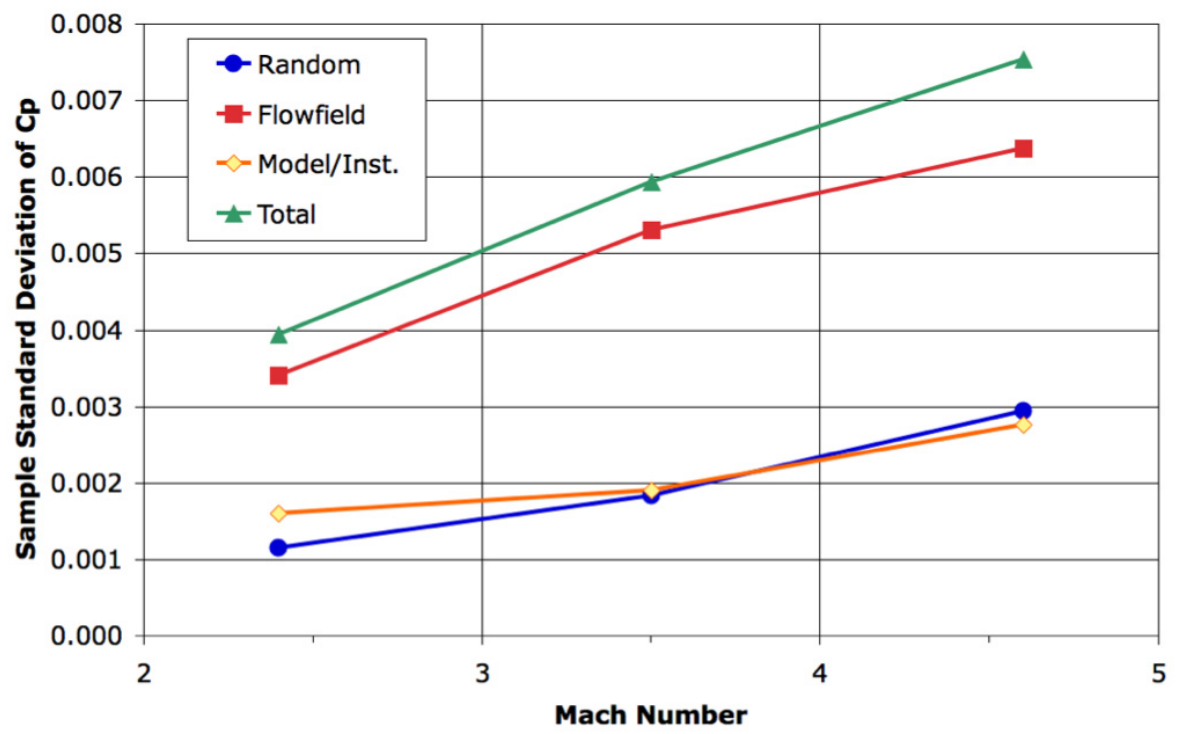

Figure 11. Variation of uncertainty with Mach number.

\section{Application of Estimated Uncertainties}

The total uncertainties given in Table 7 are applied to plots of model surface pressure coefficient for the baseline configuration in Figures 12-14 to illustrate how the uncertainties relate to the trends in the data. Figure 12 shows the radial variation of $C_{p}$ on the forebody for the baseline configuration at $\mathrm{M}_{\infty}=3.5$ and $\alpha_{T}=0^{\circ}$, and for an array of pressure ports at a circumferential location on the model of $\theta=180^{\circ}$. The set of data covers all X-Y test section locations that were tested at $\mathrm{M}_{\infty}=3.5$, and the angle of attack was chosen so as to include runs at all roll angles, as the model flowfield is nominally axisymmetric at $\alpha_{T}=0^{\circ}$. Altogether, the data set covers 31 runs and 62 data records (since there were two replicate $\alpha_{T}=0^{\circ}$ points per run), and a total of 820 individual pressure measurements. An average $C_{p}$ value was computed at each measurement location and is plotted in Figure 12 with error bars representing a $\pm 3 \sigma$-uncertainty of $\Delta \mathrm{C}_{\mathrm{p}}= \pm 0.0178$. As seen in the plot, the uncertainty bounds capture the variation of all the data, with the exception of two points that fall just outside. However, since a $\pm 3 \sigma$-uncertainty provides $99.7 \%$ coverage of the variability, it should be expected that 2 or 3 points out of a total of 820 would lie outside the uncertainty bounds.

Figure 13 provides similar plots for the baseline configuration, but this time for an angle of attack $\alpha_{T}=-4^{\circ}$ and a roll angle $\phi=0^{\circ}$, and at $\mathrm{M}_{\infty}=2.4,3.5$, and 4.6, respectively. The data are for the same array of pressure ports on the forebody as well as a longitudinal array of pressure ports on the aft body at $\theta=180^{\circ}$. The sets of data cover 11,7 , and 6 runs, respectively, over the full range of X-Y locations tested at each Mach number. The total number of pressure measurements shown in each plot are 154, 98, and 84, respectively. For each set of measurements, a trendline is drawn in Figure 13 (and subsequently in Figures 14-18) through the average $C_{p}$ value at each forebody 
radial distance and aft body axial location along with error bars representing a $\pm 3 \sigma$-uncertainty as computed for each Mach number. The angle of attack $\alpha_{\mathrm{T}}=-4^{\circ}$ was selected as a case with the aft body pressure ports in the leeside flow, where flow expansion and separation around the shoulder between the forebody and aft body would yield pressure levels on the aft body at or below the freestream static value. Again, the $\pm 3 \sigma$-uncertainties as applied to the average $C_{p}$ values show good coverage of the scatter in the data for the forebody as well as the aft body. The low pressure levels and unsteady nature of separated flow on the aft body might be expected to yield greater variation in the measurements. However, this does not appear to be the case, with the aft body results showing equal or less spread in the data than for the forebody.

Figure 14 is similar to the plots presented above, but for an angle of attack $\alpha_{\mathrm{T}}=12^{\circ}$, placing the aft body pressure ports of interest in the windside flow. The $\pm 3 \sigma$-uncertainties cover the variations in the data, with the exception for $\mathrm{M}_{\infty}=2.4$, where some of the forebody measurements fall outside the uncertainty bounds on both the high and low side. Closer examination of the residuals revealed that the measurements from Run 26 were consistently lower than those of the other runs in Figure 14 for that pressure port array, but the cause is presently unknown. An inspection of the pressure deviations from the high-accuracy monitor pressures does not uncover any issues with the calibrations of the ESP modules for those runs, although all the pressure ports in that array were measured on ESP module \#3, with the exception of one port.

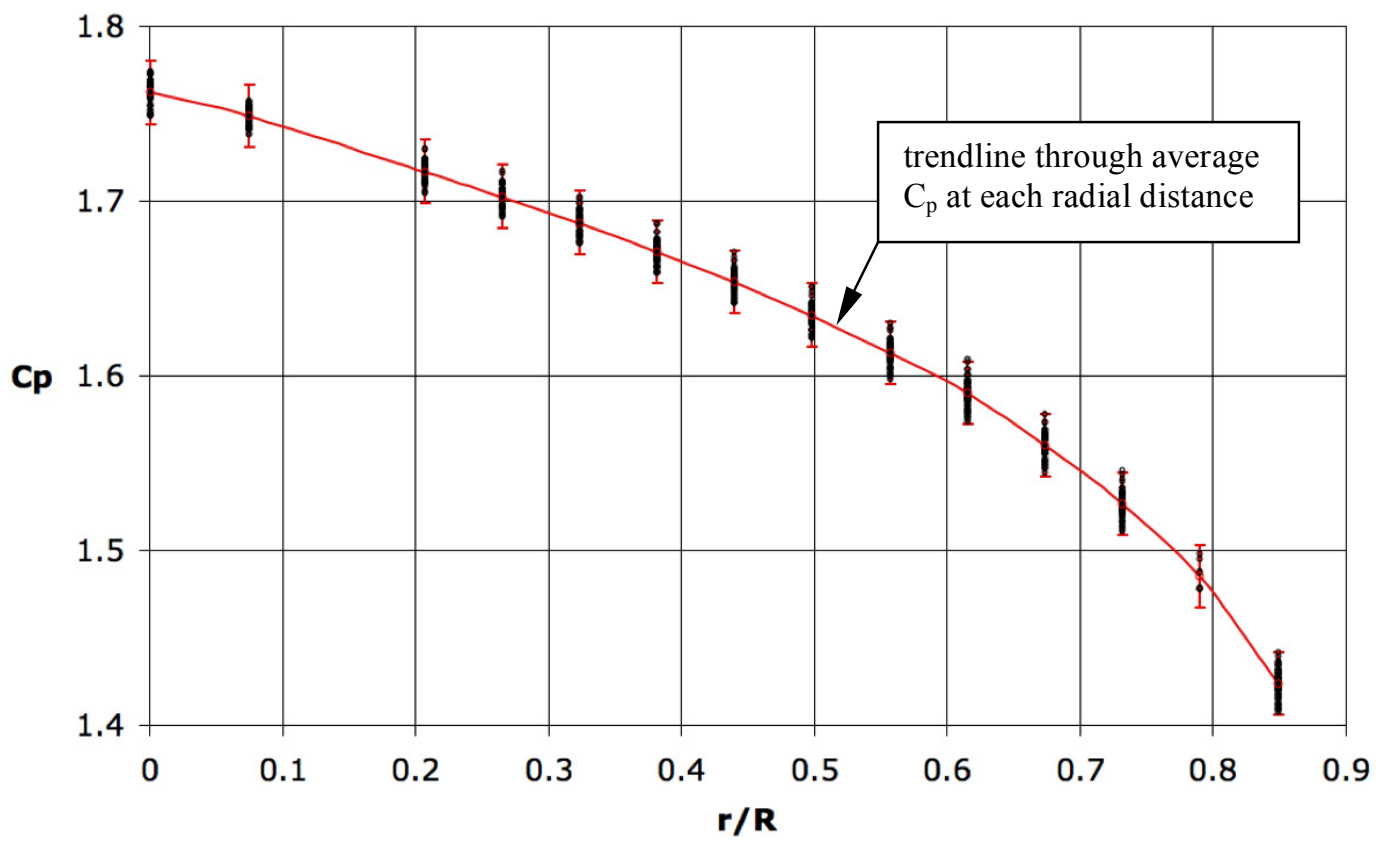

Figure 12. Radial variation of forebody $C_{P}$ on the baseline configuration for $\alpha_{T}=0^{\circ}, M_{\infty}=3.5$. 


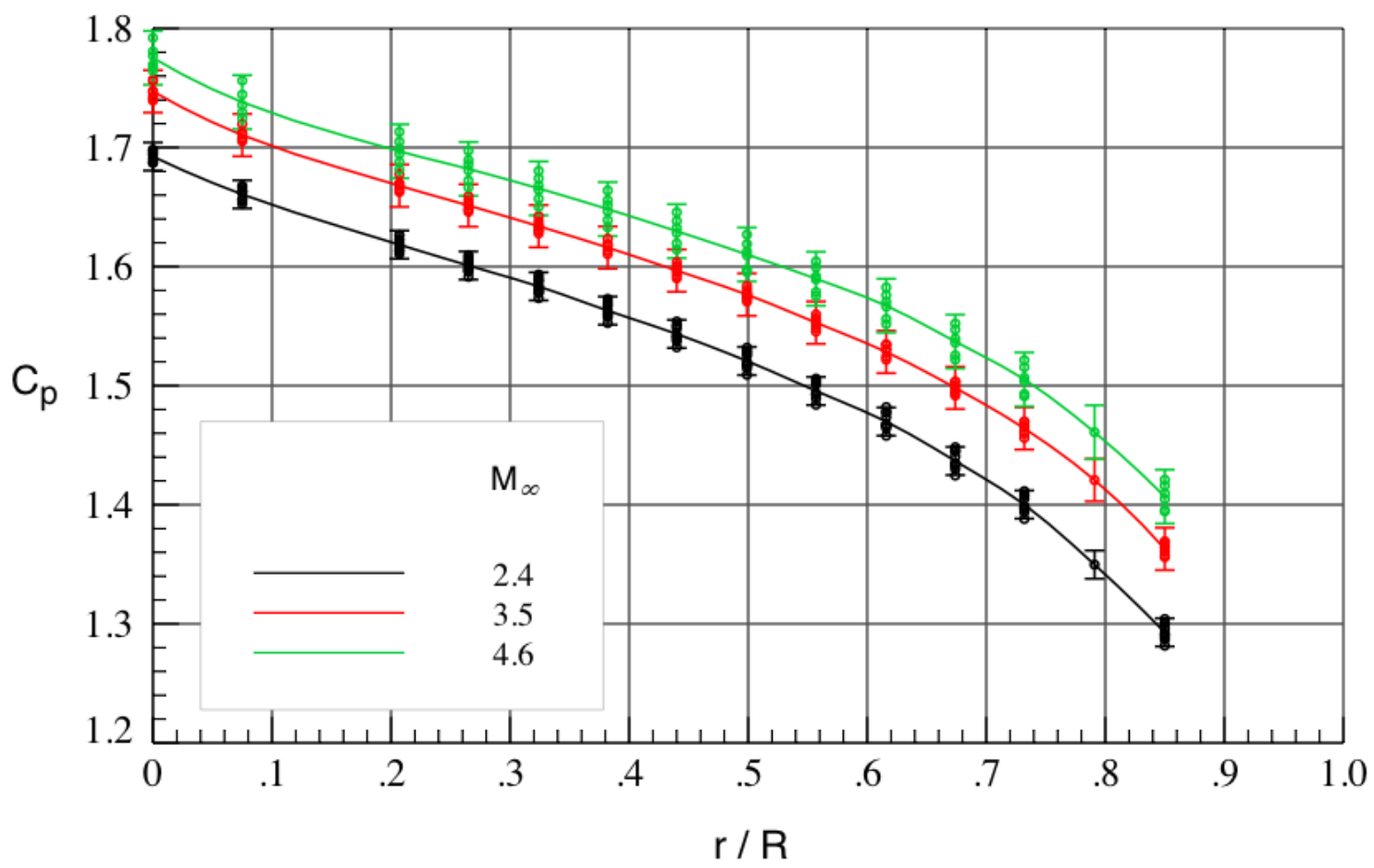

(a) Forebody

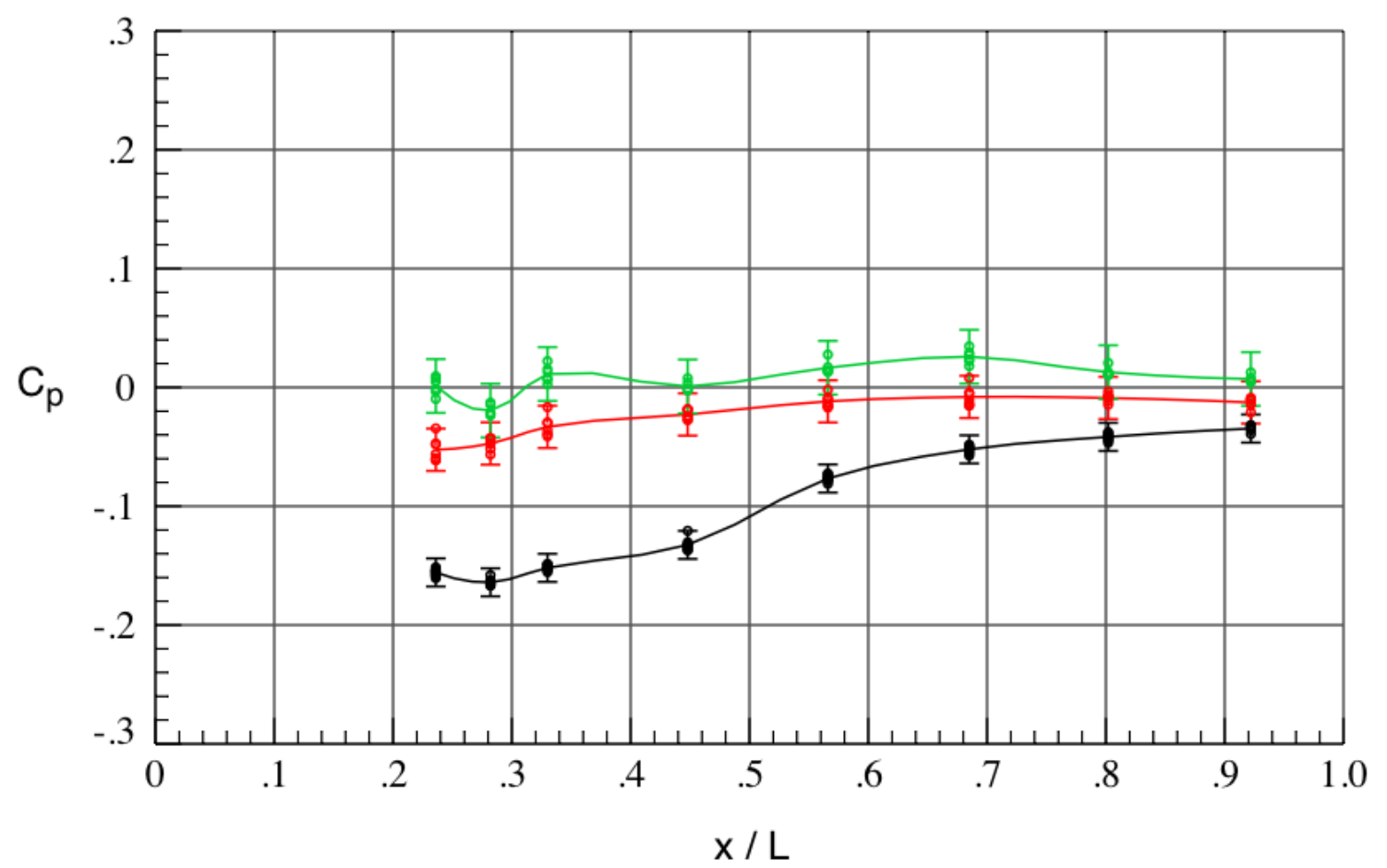

(b) Aft Body

Figure 13. Effect of $M_{\infty}$ on $C_{P}$ for the baseline configuration, $\alpha_{T}=-4^{\circ}, \phi=0^{\circ}, \theta=180^{\circ}$. 


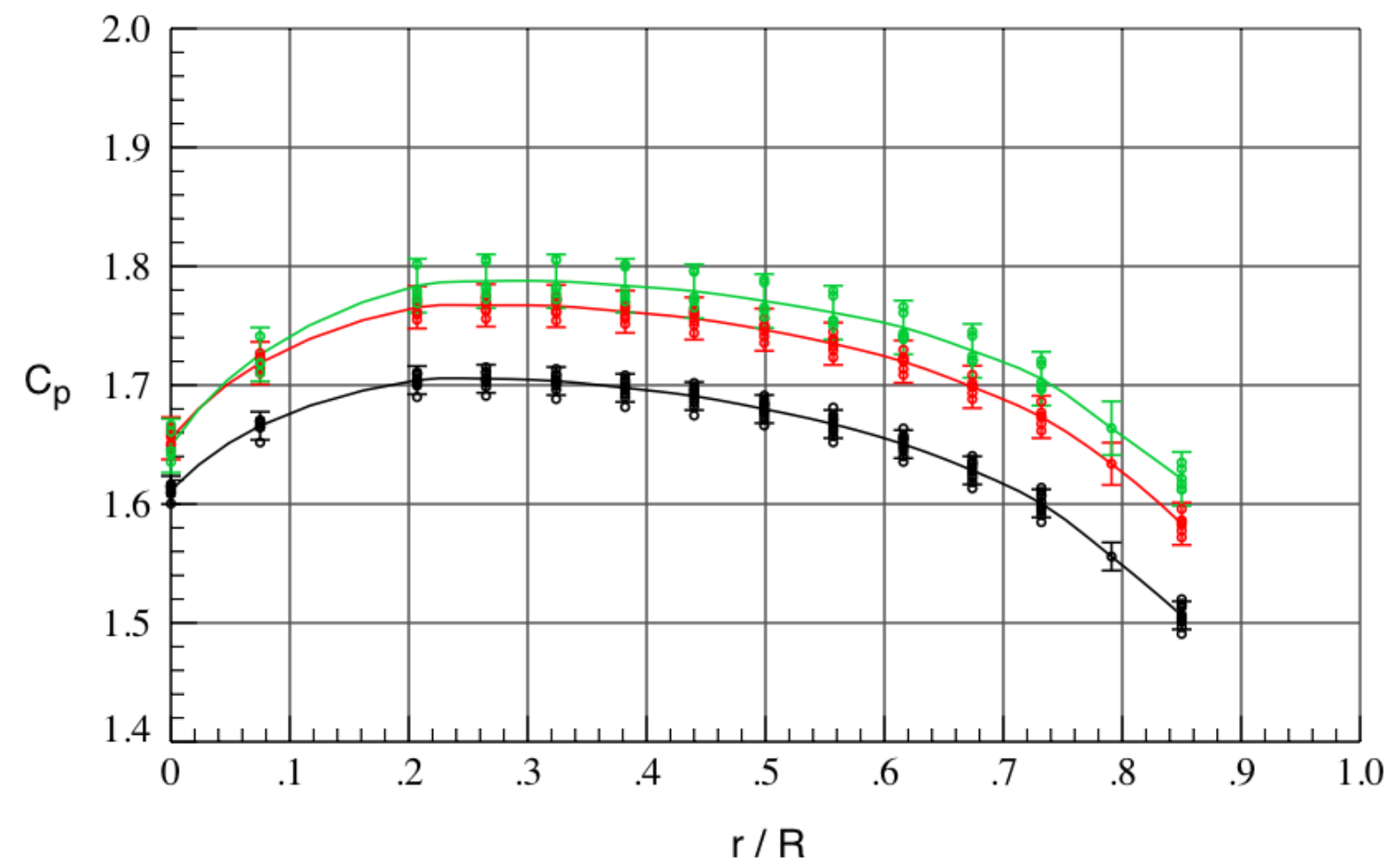

(a) Forebody

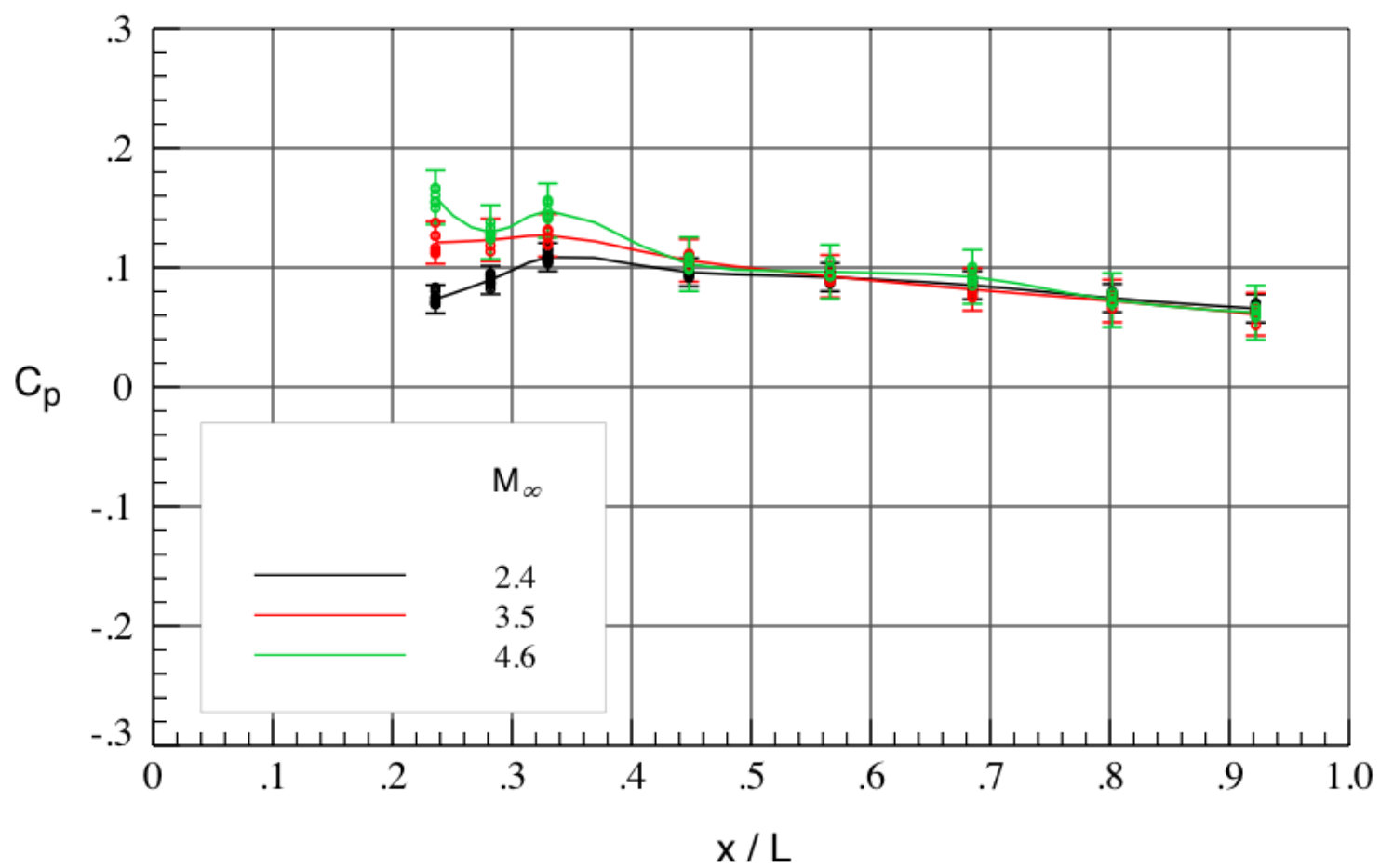

(b) Aft Body

Figure 14. Effect of $M_{\infty}$ on $C_{P}$ for the baseline configuration, $\alpha_{T}=12^{\circ}, \phi=0^{\circ}, \theta=180^{\circ}$. 
As explained earlier, the uncertainty estimates were obtained from data on the non-blowing baseline configuration to minimize or eliminate unsteady flow effects that could otherwise mask or skew the estimates of the various uncertainty components. Examples of such potential effects include phase lag and pressure amplitude effects due to the tubing between the pressure ports and ESP modules that could bias the measurements. Additionally, any unsteady flow cycles with periods approaching or exceeding the 2.5 -second data sampling interval could alter the measurements. This leaves open the question as to how applicable are the uncertainty estimates to the data acquired for blowing model configurations. Unfortunately, due to test schedule and budget limitations, very little replicate data was acquired for the powered conditions, and the test section location was not varied for any of the powered model configurations. Some comparisons can be made, however, by taking advantage of model symmetry at $\alpha_{T}=0^{\circ}$. The variations in $C_{p}$ between pairs of runs for the center-nozzle configuration at $\alpha_{T}=0^{\circ}$, thrust coefficient $\mathrm{C}_{\mathrm{T}}=2$, roll angles of $\phi=0^{\circ}$ and $180^{\circ}$, and Mach numbers of 2.4, 3.5, and 4.6 are shown in Figure 15. This case was chosen as a jet-on condition where the flow was observed via schlieren imagery to be relatively steady. As can be seen, the variations in the data between the two runs, for the same pressure ports shown in the earlier plots, are well within the uncertainty limits established from the baseline configuration at each Mach number on both the forebody and aft body, albeit for a limited number of replicates. But given that the runs were acquired back-to-back, separated at most by 7 minutes, and provided that the flow structure was relatively steady for this configuration and angle of attack, it is not unexpected that there would be limited scatter in the data.

A few replicate runs were available for the tri-nozzle configuration, and one such case is shown in Figure 16 for three runs at $\mathrm{M}_{\infty}=3.5, \phi=0^{\circ}, \mathrm{C}_{\mathrm{T}}=1$, and angles of attack $\alpha_{\mathrm{T}}=0,8$, and $16^{\circ}$. It was observed in the high-speed schlieren imagery that the shock wave/jet plume interactions were unsteady for these combinations of configuration and angles of attack, so this case was chosen to test whether uncertainty limits determined for a quasi-steady flow field would be applicable to a known unsteady flow. In Figure 16, the uncertainty bounds do not quite fully encompass the variations in the data on the forebody, with some data points falling outside of the uncertainty limits, particularly at the highest angle of attack where the flow was observed to be the most unsteady. It is noted that for the three runs, approximately 30 minutes elapsed between data acquisition for the first two runs, while roughly 24 hours, and a minimum of two ESP calibration cycles, passed between the second and third runs.

Additional replicate runs were available for the tri-nozzle configuration at $\mathrm{M}_{\infty}=4.6$ for roll angles of $\phi=0^{\circ}$ and $180^{\circ}$ and thrust coefficients of $\mathrm{C}_{\mathrm{T}}=2$ and 3. Figure 17 show pairs of runs at $\mathrm{C}_{\mathrm{T}}=2$ and $\phi=0^{\circ}$ and $180^{\circ}$, respectively, for an angle of attack $\alpha_{\mathrm{T}}=12^{\circ}$ and the same pressure ports presented in the previous plots. In both cases, the variations in the data between the two runs fall well within the uncertainty limits, with the largest scatter occurring on the aft body. The elapsed time between replicate runs was approximately 16 hours. A similar result is noted in Figure 18, again for $\phi=0^{\circ}$ and $180^{\circ}$, respectively, $\alpha_{T}=12^{\circ}$, but for $C_{T}=3$, and an elapsed time between runs of roughly 42 hours. During the test, it was observed in the schlieren imagery that the flow structure for the trinozzle configuration was much steadier for $\phi=180^{\circ}$ and $\alpha_{T}>0^{\circ}$ than for the corresponding $\phi=0^{\circ}$ case [14]. However, there is little apparent difference in repeatability shown between the two roll angles in Figure 17 and Figure 18. With so little replicate jet-on data, and with no assessment of flowfield non-uniformity uncertainty for the powered runs, one cannot definitively state that the uncertainties derived from the baseline, non-powered configuration should cover the variations in the powered results, even though the plots in Figure 15 through Figure 18 may indicate so. Because unsteady flow effects could bias the measured pressure data, the authors caution against using the herein computed uncertainty limits for the jet-on data. This caution should be extended in general to mean that uncertainties obtained from any set of experimental data should apply only to the data from which they were derived.

Since the SRP experiment was performed for CFD model validation purposes, it is of interest to see how well the CFD predictions compare with the experimental data. Such a comparison is shown in Figure 19 - taken from [3] for the non-blowing baseline configuration at $\mathrm{M}_{\infty}=4.6$ and angles of attack of 0,12 , and $20^{\circ}$. The agreement is generally very good on both the forebody and aft body of the model, although some of the predictions fall outside of the experimental uncertainty limits in a few locations. Additional comparisons are provided in [3] for both jet-off and jet-on cases, and information about the CFD computations for SRP are given in [3] and [5]. 


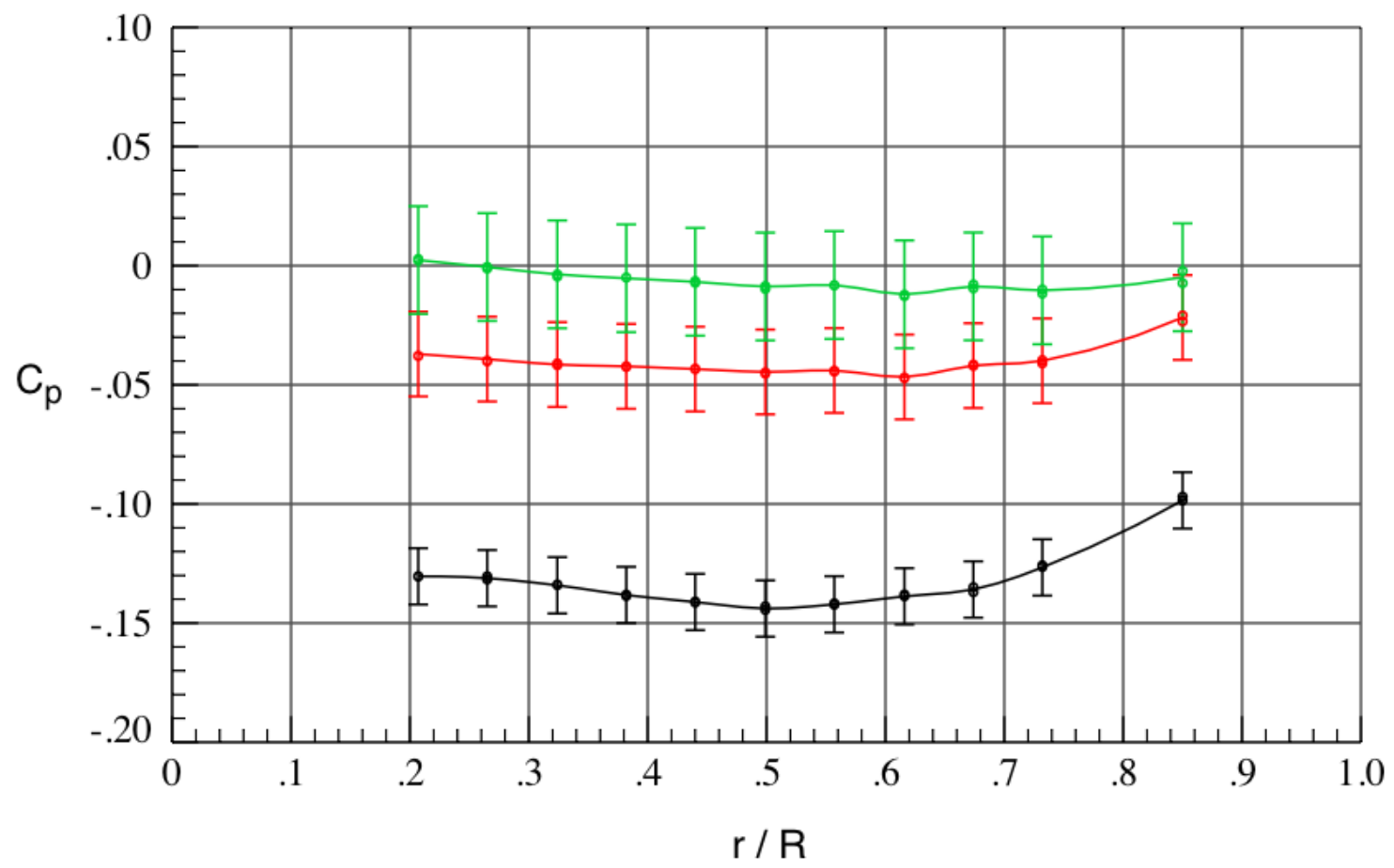

(a) Forebody

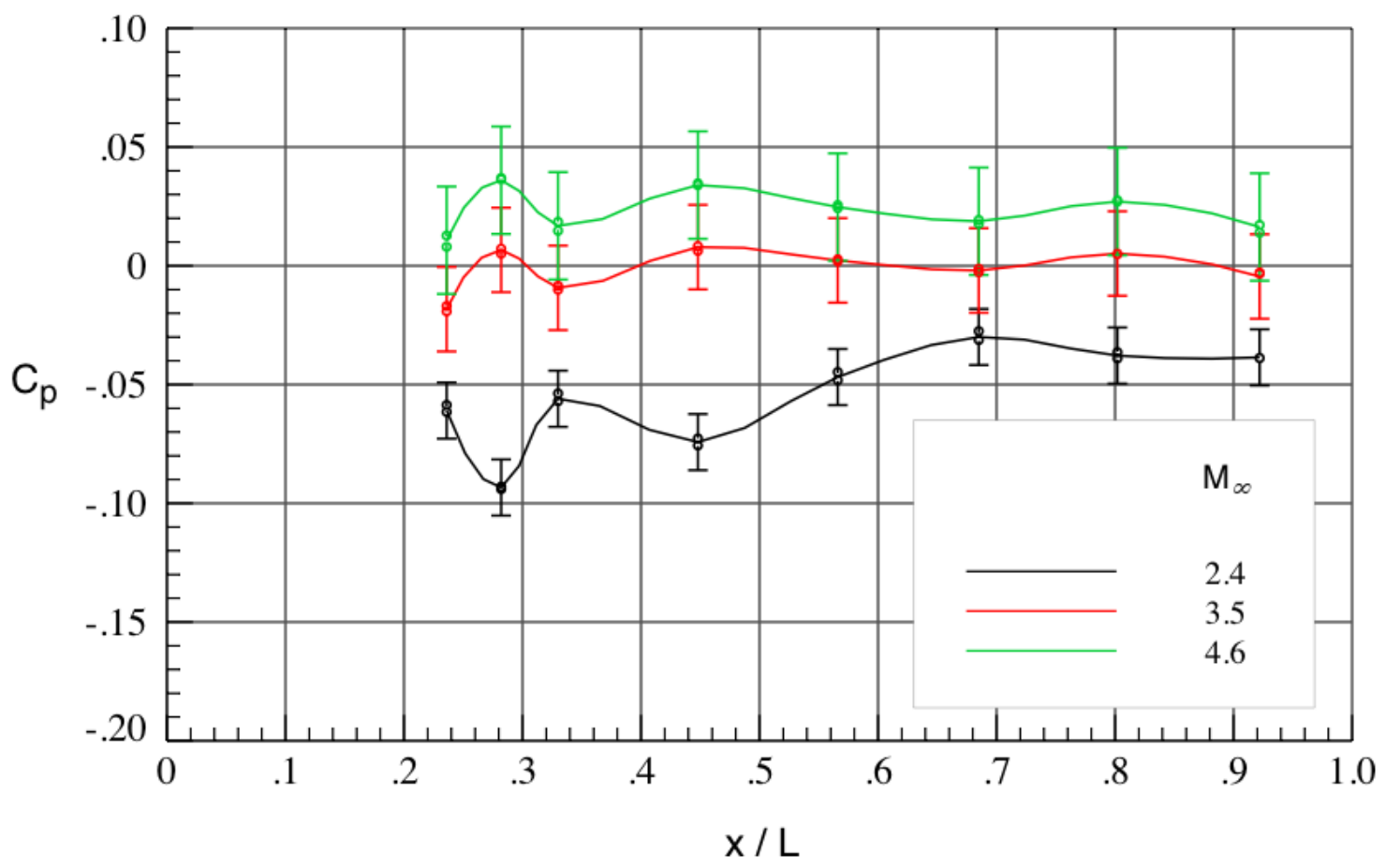

(b) Aft Body

Figure 15. Effect of $M_{\infty}$ on $C_{P}$ for the center-nozzle configuration, $\alpha_{T}=12^{\circ}, \phi=0^{\circ}, C_{T}=2, \theta=180^{\circ}$. 


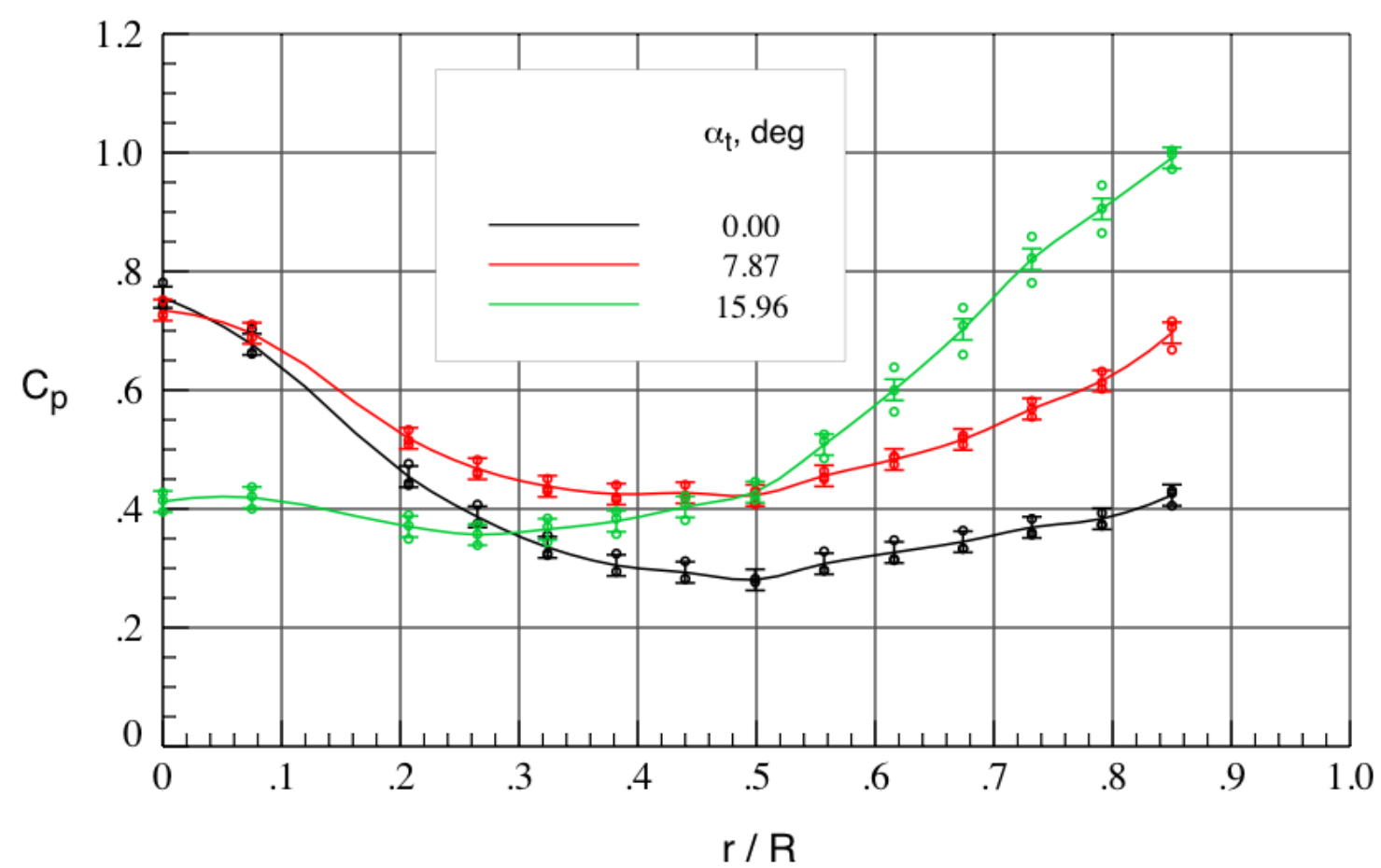

(a) Forebody

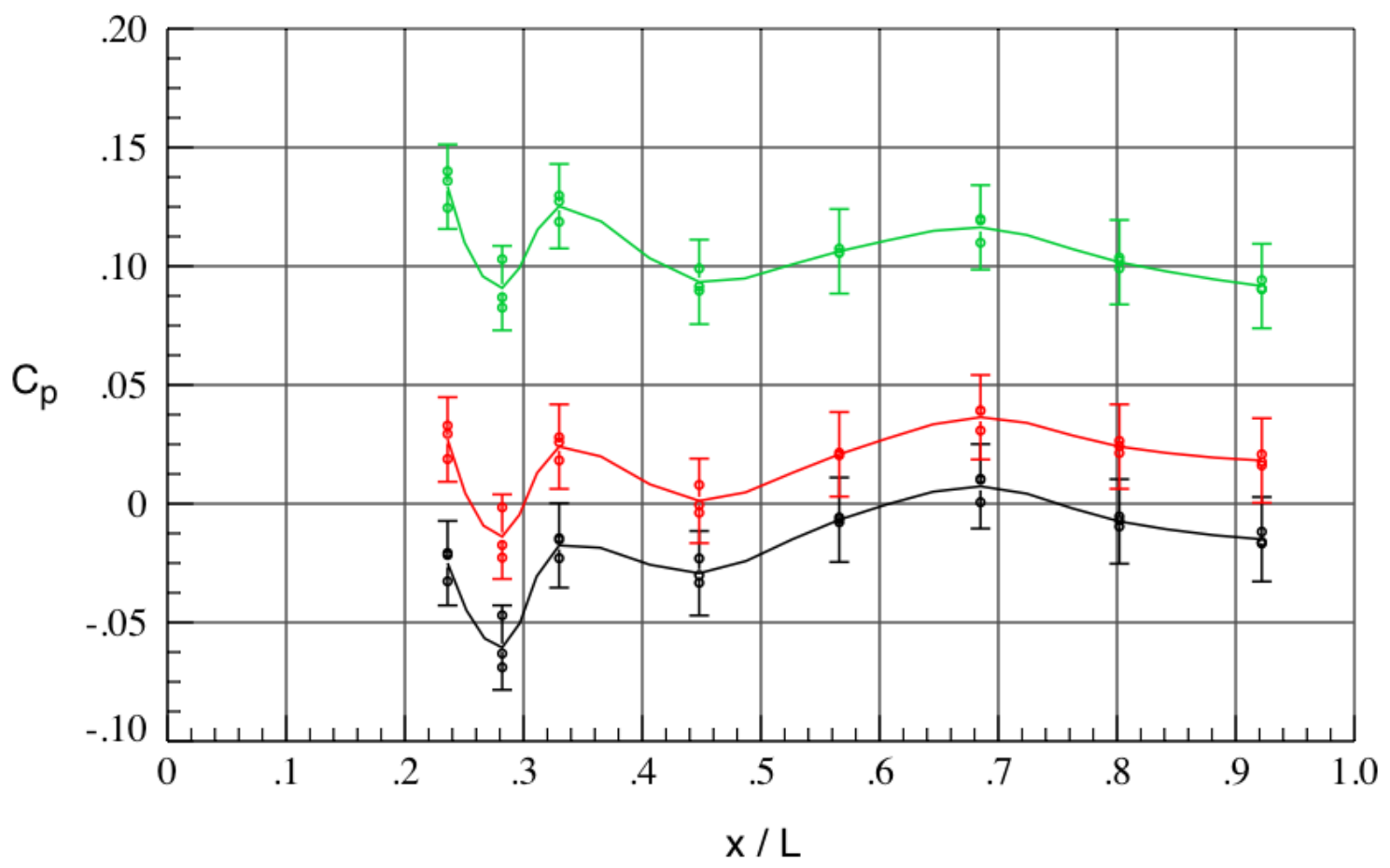

(b) Aft Body

Figure 16. Effect of $\alpha_{T}$ on $C_{P}$ for the tri-nozzle configuration, $M_{\infty}=3.5, \phi=0^{\circ}, C_{T}=1, \theta=180^{\circ}$. 


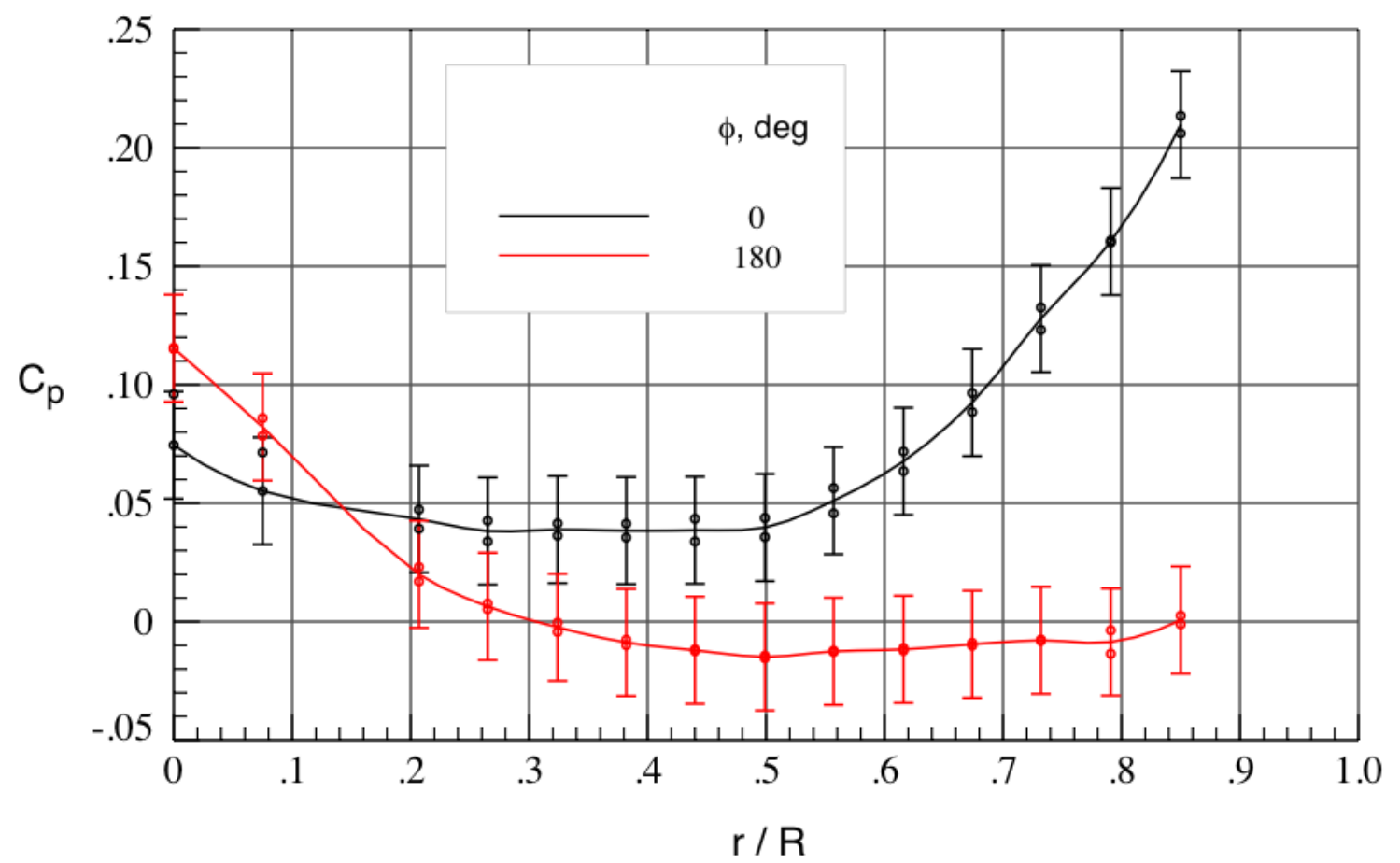

(a) Forebody

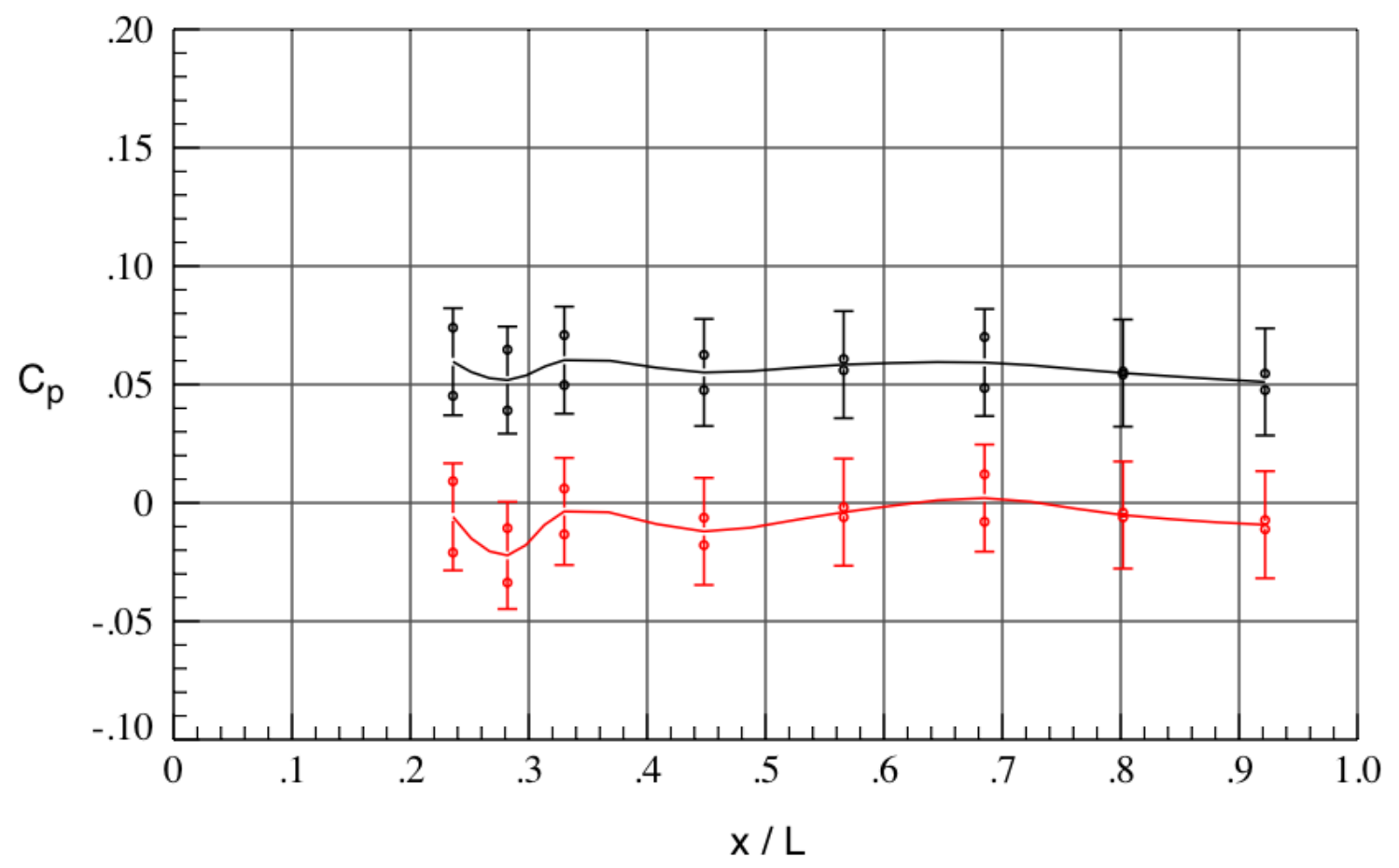

(b) Aft Body

Figure 17. Effect of $\phi$ on $C_{P}$ for the tri-nozzle configuration, $M_{\infty}=4.6, \phi=0^{\circ}, C_{T}=2, \theta=180^{\circ}$. 


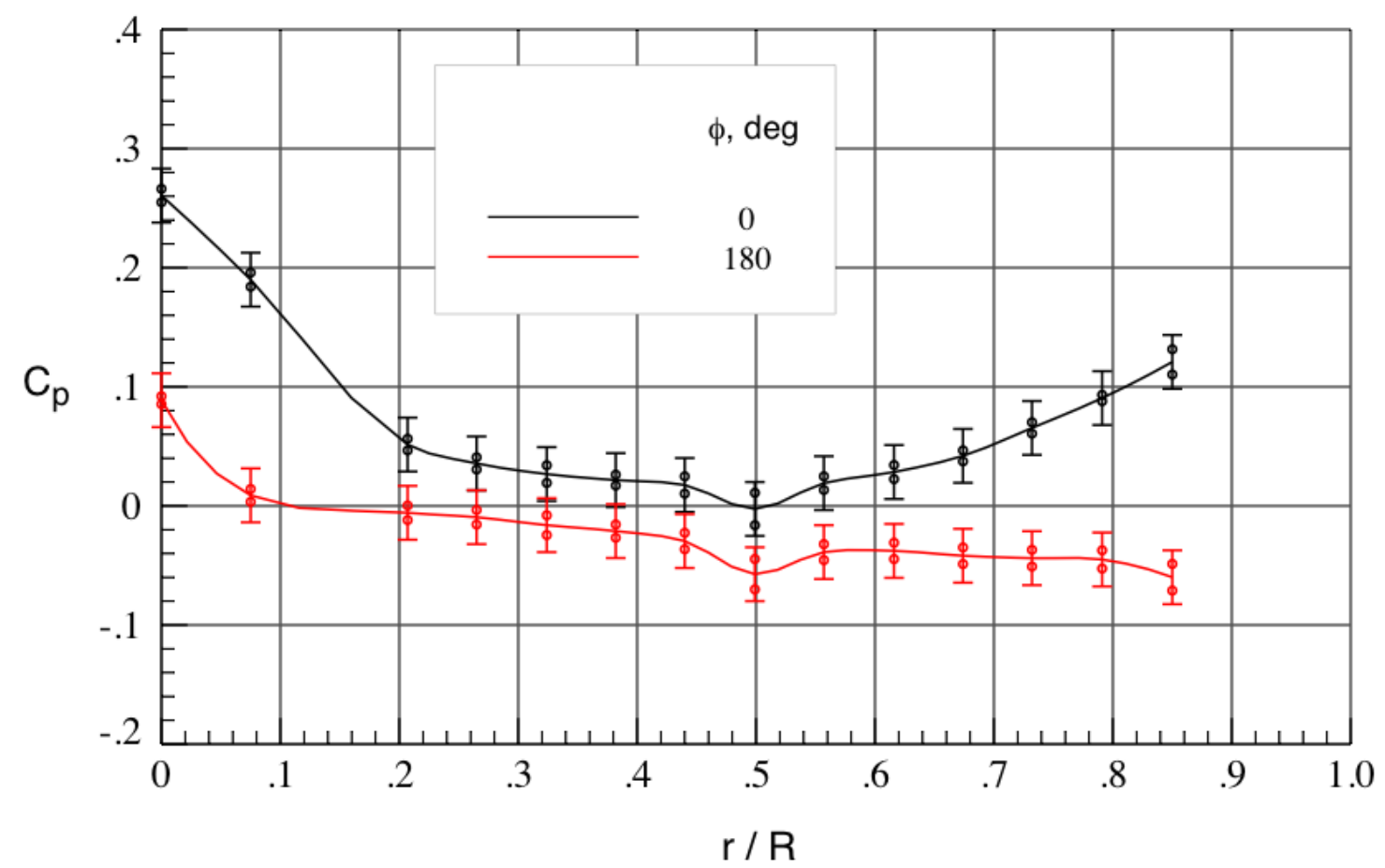

(a) Forebody

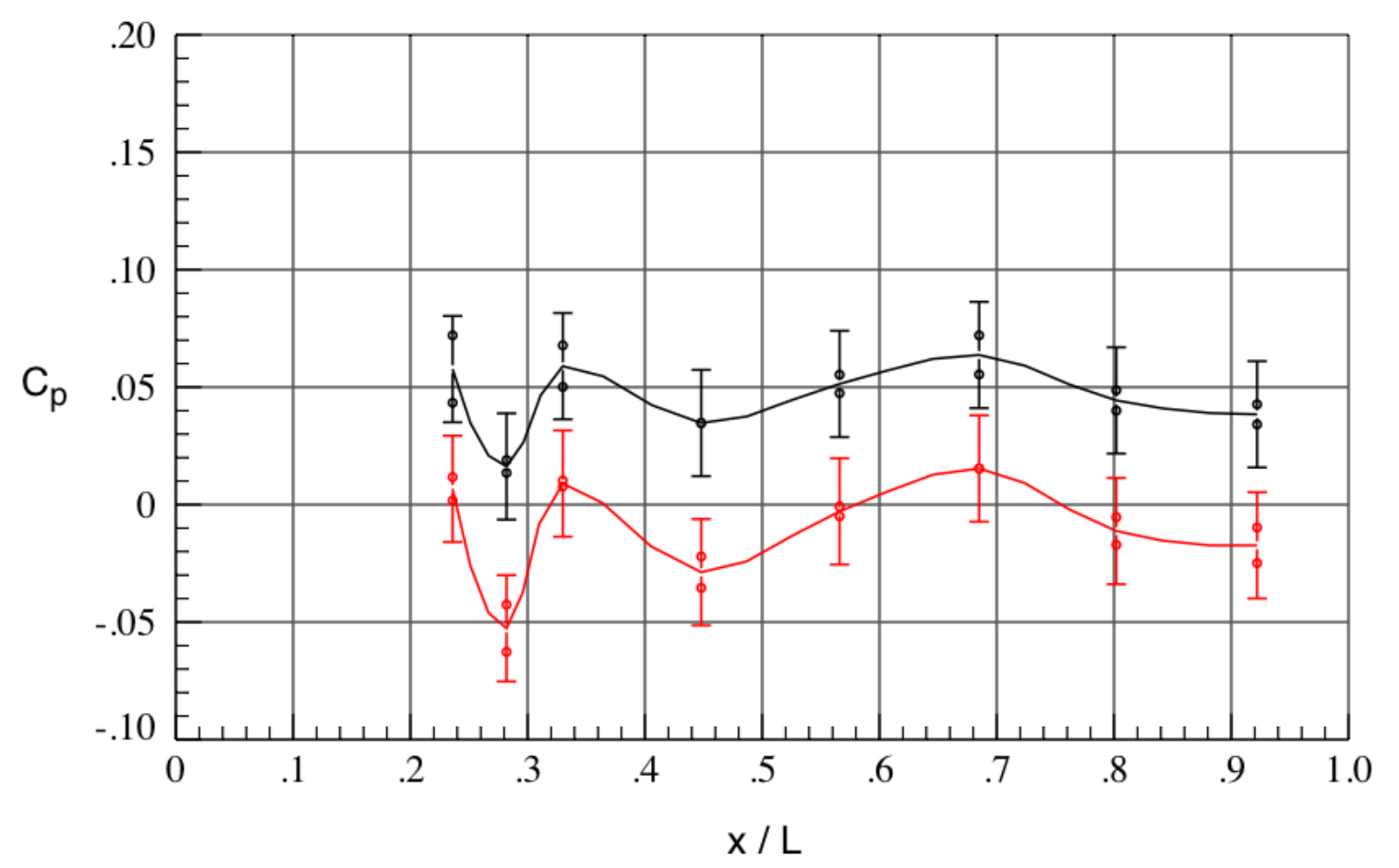

(b) Aft Body

Figure 18. Effect of $\phi$ on $C_{P}$ for the tri-nozzle configuration, $M_{\infty}=4.6, \phi=0^{\circ}, C_{T}=3, \theta=180^{\circ}$. 

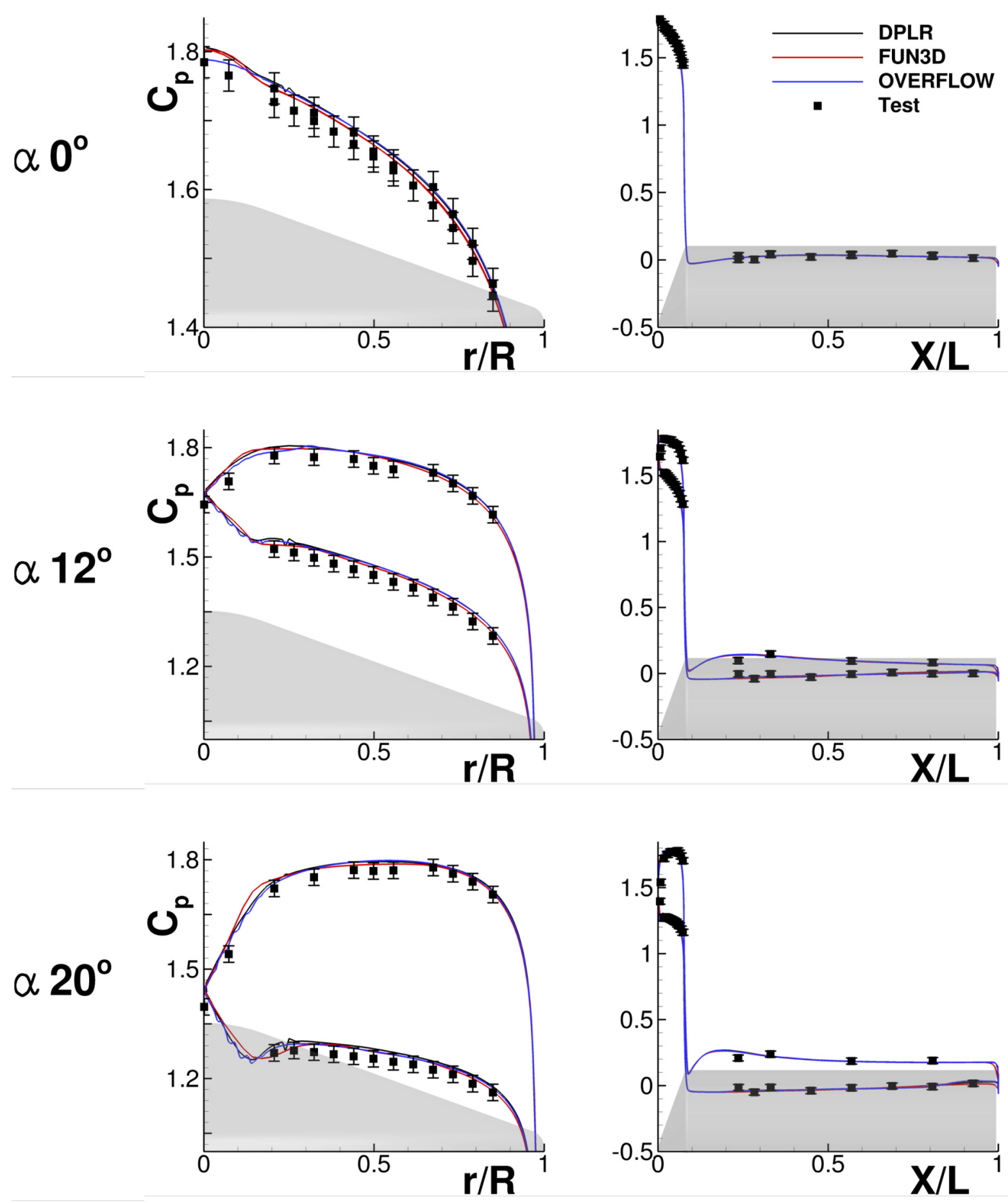

Figure 19. Comparison of CFD predictions with experiment along the windward and leeward rays for the baseline configuration, Mach 4.6, Run 283 (taken from [3]). 


\section{Summary}

A computational model validation experiment for SRP was run in the NASA LaRC UPWT at Mach numbers of 2.4, 3.5, and 4.6. The purpose of the validation experiment was to conduct a high-quality validation experiment for use in CFD model validation as well as to acquire basic fluid dynamics information for a representative planetary configuration with forward-firing jets. As part of the first experimental goal, surface pressure data were obtained on the baseline non-thrusting model configuration over a range of angle of attack, roll angle, test section axial and lateral locations, and for a number of replicate runs. These data were used to determine the components of uncertainty for random error, flowfield non-uniformity effects, and model geometry/instrumentation effects, as well as the overall uncertainty. The relative percentage distribution of the uncertainty components were found to be in qualitative agreement with that from other experiments reported in the literature. Flowfield non-uniformity was found to be the dominant effect, accounting for $71-80 \%$ of the total variance, depending on Mach number. The random error and model geometry uncertainties were found to be roughly equivalent in their respective contributions to the overall uncertainty. Plots of the pressure coefficient variation on both the forebody and aft body show that the scatter in the data is properly captured by the computed uncertainty limits for the non-powered configuration, but not necessarily for the powered runs. The authors caution against applying the uncertainty limits - derived from the non-powered baseline configuration - to the powered data due to unsteady flow effects that could bias the pressure measurements.

Future work includes determining pressure coefficient uncertainty estimates for the powered data from the limited number of Kulite pressure transducers on the model. Additionally, a similar uncertainty analysis will be performed for a recent test of this same SRP model in the NASA Ames 9x7-Foot Supersonic Wind Tunnel, providing a comparison of uncertainty limits between the two facilities at an overlapping test condition of Mach 2.4.

\section{Acknowledgments}

The authors would like to acknowledge the support of NASA's Exploration Technology Development and Demonstration (ETDD) Program and Fundamental Aeronautics Program (FAP). The work documented herein was performed jointly by the ETTD's EDL Technology Development Project as well as FAP's Hypersonics Project, both of which are managed at the NASA Langley Research Center and supported by the NASA Ames Research Center, the NASA Johnson Space Center, and the Jet Propulsion Laboratory. Particular recognition goes to Scott Berry, Karl Edquist, Bil Kleb, Guy Schauerhamer, Kerry Zarchi, Ashley Korzun, Chris Laws, Courtney Spells, Aaron Fuchs, Bryan Falman, Ricky Hall, and Steve Jones for their efforts in the design, planning, and execution of this experiment. A special thank you is extended to Bruce Graham for his helpful suggestions with the DESL macro scripts that were used in the analysis of these data.

\section{References}

[1] Zang, T. A., Cianciolo, A. M. D., Kinney, D. J., Howard, A. R., Chen, G. T., Ivanov, M. C., Sostaric, R. R., and Westhelle, C. H., "Overview of the NASA Entry, Descent and Landing Systems Analysis Study", AIAA Paper 2010-8649, September 2010.

[2] Edquist, K. T., Dyakonov, A. A., Korzun, A. M., Shidner, J. D., Studak, J. W., Tigges, M. A., Kipp, D. M., Prakash, R., Trumble, K. A., and Dupzyk, I. C., "Development of Supersonic Retro-Propulsion for Future Mars Entry, Decent, and Landing Systems," AIAA Paper 2010-5046, June 2010.

[3] Schauerhamer, D. G, Trumble, K. A., Kleb, W. L, Carlson, J-R., and Edquist, K. T., "Continuing Validation of Computational Fluid Dynamics for Supersonic Retropropulsion,” AIAA Paper 2012-0864, January 2012.

[4] Korzun, A. M., Braun, R. D., and Cruz, J. R., "Survey of Supersonic Retropropulsion Technology for Mars Entry, Descent, and Landing," Journal of Spacecraft and Rockets, Vol. 46, No. 5, 2010, pp. 929-937.

[5] Trumble, K. A., Schauerhamer, D. G., Kleb, W. L., Carlson, J-R., Buning, P. G., Edquist, K. T., and Barnhardt, M. D., "An Initial Assessment of Navier-Stokes Codes Applied to Supersonic Retro-Propulsion,” AIAA Paper 2010-5047, June 2010.

[6] Oberkampf, W. L., and Trucano, T. G., "Verification and Validation in Computational Fluid Dynamics," Progress in Aerospace Sciences, Vol. 38, No. 3, 2002, pp. 209-272.

[7] Berry, S. A., Laws, C. T., Kleb, W. L., Rhode, M. N., Spells, C., Mccrea, A. C., Trumble, K. A., Schauerhamer, D. G., and Oberkampf, W. L., "Supersonic Retro-Propulsion Experiment Design for Computational Fluid Dynamics Model Validation," IEEEAC Paper 1499, March 2011.

[8] Oberkampf, W. L., and Roy, C. J., Verification and Validation in Scientific Computing, Cambridge University Press, Cambridge, U.K., 2010, pp. 409-422.

[9] Kammeyer, M. E., "Wind Tunnel Facility Calibrations and Experimental Uncertainty," AIAA Paper 98-2715, June 1998. 
[10] Oberkampf, W. L., Martellucci, A., and Kaestner, P. C., "SWERVE Surface Pressure Measurements at Mach Numbers of 3 and 8 (U)," Report SAND84-2149, Sandia National Laboratories, Albuquerque, NM, 1985 (SECRET Formerly Restricted Data).

[11] Oberkampf, W. L., and Aeschliman, D. P., "Joint Computational/Experimental Aerodynamics Research on a Hypersonic Vehicle, Part 1: Experimental Results," AIAA Journal, Vol. 30, No. 8, 1992, pp. 2000-2009.

[12] Aeschliman, D. P., and Oberkampf, W. L., "Experimental Methodology for Computational Fluid Dynamics Code Validation," AIAA Journal, Vol. 36, No. 5, 1998, pp. 733-741.

[13] Oberkampf, W. L., Aeschliman, D. P., Henfling, J. F., and Larson, D. E., "Surface Pressure Measurements for CFD Code Validation in Hypersonic Flow," AIAA Paper 95-2273, June 1995.

[14] Berry, S. A., Rhode, M. N., Edquist, K. T., and Player, C. J., "Supersonic Retropropulsion Experimental Results from the NASA Langley Unitary Plan Wind Tunnel," AIAA Paper 2011-3489, June 2011.

[15] Rhode, M. N., and Oberkampf, W. L., "Estimation of Uncertainties for Supersonic Retropropulsion Test 1853 in the NASA Langley Research Center Unitary Plan Wind Tunnel," Report EDL-01-TR-9217, October 2011.

[16] "Guide to the Expression of Uncertainty in Measurement," International Organization for Standardization (ISO), Geneva, Switzerland, 1995.

[17] "Uncertainty in Measurement - Part 3: Guide to the Expression of Uncertainty in Measurement," International Organization for Standardization (ISO), ISO/IEC Guide 98-3, Geneva, Switzerland, 2008.

[18] "U.S. Guide to the Expression of Uncertainty in Measurement," American National Standards Institute, Boulder, CO, 1997.

[19] "Assessment of Experimental Uncertainty With Application to Wind Tunnel Testing," AIAA-S-071A-1999, American Institute of Aeronautics and Astronautics, Reston, VA, 1999.

[20] "Assessing Experimental Uncertainty - Supplement to AIAA-S-071A-1999," AIAA-G-045-2003, American Institute of Aeronautics and Astronautics, Reston, VA, 2003.

[21] Montgomery, D. C., Design and Analysis of Experiments, $5^{\text {th }}$ Ed., John Wiley \& Sons, New York, 2000.

[22] Box, G. E. P., Hunter, J. S., and Hunter, W. G., Statistics for Experimenters: Design, Innovation, and Discovery, $2^{\text {nd }}$ Ed., John Wiley \& Sons, New York, 2005.

[23] Hinkelmann, K., and Kempthorne, O., Design and Analysis of Experiments: Volume 1 - Introduction to Experimental Design, $2^{\text {nd }}$ Ed., John Wiley \& Sons, New York, 2008.

[24] DeLoach, R., "Blocking: A Defense Against Long-Period Unexplained Variance in Aerospace Ground Testing," AIAA Paper 2003-0650, January 2003.

[25] DeLoach, R., and Micol, J. R., "Comparison of Resource Requirements for a Wind Tunnel Test Designed with Conventional vs. Modern Design of Experiments Methods," AIAA Paper 2011-1260, January 2011.

[26] Jackson, C. M. Jr., Corlett, W. A., and Monta, W. J., Description and Calibration of the Langley Unitary Plan Wind Tunnel, NASA TP-1905, November 1981.

[27] http://www.vigyan.com/desl. Last accessed May 18, 2012.

[28] Nagai, S., and Hidetoshi, I., "Uncertainty Identification of Supersonic Wind-Tunnel Testing," Journal of Aircraft, Vol. 48, No. 2, 2011, pp. 567-577. 